Social Optimum, Heterogeneous Workers and Firms in the Labour Market with On-the-Job-Search

Erdenebulgan Damdinsuren 


\title{
Social Optimum, Heterogeneous Workers and Firms in the Labour Market with On-the-Job Search*
}

\author{
Erdenebulgan Damdinsuren ${ }^{\dagger \ddagger}$
}

January 8, 2021

\begin{abstract}
This paper develops a search model with heterogeneous workers, firms, and on-the-job search. Employed low-skilled workers are allowed to seek better paid jobs at high productivity firms. Low productivity firms make take-it-or-leave-it wage offers, whereas high productivity firms use Nash bargaining over wages. There are two important sources of inefficiency in the model besides the well-known classical search externality. First, low-skilled workers do not have any bargaining power when they are employed at low productivity firms. Second, the two types of workers are pooled in the same submarket. We demonstrate that lump-sum transfers paid to workers can internalize these inefficiencies. Moreover, both types of firms may benefit from the increase in the supply of low-skilled workers when the productivity difference in the two jobs for these workers is large, as a result the overall wage gap among workers increase. On the contrary, when the productivity difference is small, the effects are reversed. Finally, both types of firms emerge in the equilibrium when firms are allowed to open vacancies in both submarkets. On the one hand, it is attractive for firms to open vacancies in the low productivity submarket since they pay low wages to workers. On the other hand, it is also profitable for firms to open vacancies in the high productivity submarket because the probability of jobs being filled with low-skilled workers increase significantly, even though the bargained wages of high-skilled workers increase.
\end{abstract}

JEL classification: J31, J38, J64

Keywords: On-the-job search, Nash bargaining, take-it-or-leave-it, wage dispersion

${ }^{*}$ This work has received funding from the European Unions Horizon 2020 research and innovation programme under the Marie Skodowska-Curie grant agreement No 721846, Expectation and Social Influence Dynamics in Economics (ExSIDE).

${ }^{\dagger}$ The author would like to thank Anna Zaharieva and Luca Colombo for their substantial input and guidance during the development of this paper. The author also greatly appreciate the helpful comments of Sevak Alaverdyan, Alessandro Basurto, Lasha Chochua, Herbert Dawid, Jasper Hepp, Damba Lkhagvasuren, Mariya Mitkova as well as conference participants in Louvain-la-Neuve, Ulaanbaatar, and BiGSEM colloquium. Insightful comments from CLE (Complexity Lab in Economics) research group are gratefully acknowledged.

${ }^{\ddagger}$ E-mail: erdenbulgan.damdinsuren@uni-bielefeld.de Tel.: +49-521-106-4864, Bielefeld Graduate School of Economics and Business, Bielefeld University, 33615 Bielefeld, Germany; Department of Economics and Finance, Catholic University, 20123 Milan, Italy. 


\section{Introduction}

The purpose of this paper is to examine the role of on-the-job search and the workers' skill composition on labour market equilibrium while focusing on the welfare of the labour force. Although there are a number of studies that allow either worker heterogeneity, or firm heterogeneity and on-the-job search, little is known about the welfare implications of the combination of the three features. To fill this gap, we develop an equilibrium search model with heterogeneous workers and firms by incorporating on-the-job search with exogenous and endogenous wage determination mechanisms. In this setup, we show that novel externality effects arise across different skill levels of workers. Numerical results show that in such an economy, the government can generate substantial welfare gains using redistributive transfers.

More precisely, we extend Masui (2011) by allowing heterogeneity of workers. Workers are heterogeneous with respect to their skills. Low and high skilled unemployed workers are restricted to search jobs at low and high productivity firms, respectively. However, low-skilled workers are allowed to seek a better job at high productivity firms while being employed. Firms are heterogeneous with respect to their wage setting mechanisms as well. Low productivity firms make take-it-or-leave-it wage offers, while high productivity firms use Nash bargaining over wages.

We prove the existence of a decentralized equilibrium in this framework and show that the equilibrium is constraint inefficient even if the Hosios condition holds. In addition to well-known classical search externality (Hosios 1990; and Pissarides 2000), there are two important sources of inefficiency in the model. The first one is that low-skilled workers do not have any bargaining power in the low productivity submarket. In this market, vacancies are created when the expected cost equals to the expected social surplus. In contrast, in the decentralized equilibrium firms create vacancies when the expected cost equals to the expected profit. Since workers employed at low productivity firms lack of bargaining power, in the decentralized equilibrium firms obtain the full amount of the total job surplus, whereas the social planner would give only a fraction of the total surplus to the firms. This increases the number of vacancies and reduces the equilibrium unemployment rates of low-skilled workers below the socially efficient level.

The second source of inefficiency stems from the fact that the two types of workers are pooled in the high productivity submarket. In general, low-skilled workers may impose either a negative or positive externality on high-skilled workers. When low-skilled workers create higher job surplus than high-skilled workers, it encourages high productivity firms to create more vacancies. Meaning that every additional low-skilled worker searching in the high productivity submarket increases firm's profit, thus imposing a positive externality on high-skilled workers. Moreover, reservation wages for low-skilled workers are low, as they expect to be able to find better jobs in

the future. In this scenario, the optimal policy is associated with increasing reservation wages of low-skilled workers and decreasing high-skilled workers' rents. When low-skilled workers create lower job surplus than high-skilled workers, the external effects are reversed. Intuitively, every additional high-skilled worker searching in the high productivity submarket increases the expected profits of firms and imposes a positive externality on low-skilled workers. The optimal policy is associated with increasing high-skilled workers' rent and again increasing reservation wages for low-skilled workers. This scenario is supported by numerical results with baseline 
parameters. We demonstrate that lump-sum transfers paid to workers can correct these inefficiencies. The net welfare gain is estimated to be close to $3.02 \%$. These findings indicate that the social welfare can be potentially improved if in parallel to this mechanism socially disadvantaged workers compensated properly.

Next, we analyze the effect of workers' skill composition. Both types of firms benefit from increasing the fraction of low-skilled workers more, while the productivity difference of being employed at low and high productivity firms for low-skilled workers is significant. When the supply of low-skilled workers increases, low productivity firms gain higher profits by paying lower wages to these workers. It is because unemployed low-skilled workers accept their first jobs immediately. Therefore, more low-skilled workers get experienced and they look for better paid jobs at high productivity firms. As it is also profitable for the high productivity firms to hire more experienced low-skilled workers, these firms create more vacancies. Similar results are reported by Machin and Manning (1997), Acemoglu (1999) and Albrecht and Vroman (2002) in the sense that the increase in the supply of experienced low-skilled workers encourages firms to create more high productivity jobs which causes greater wage dispersion. In contrast, when the productivity difference is small, the effects are reversed. In this case, seeking better paid jobs at high productivity firms for low-skilled workers is not as attractive as before. Thus, the decrease in the reservation wages of low-skilled workers is moderated and the bargained wages of high-skilled workers will not increase as significantly as before. As a result, fewer vacancies are created in both submarkets.

Further, our model exhibits wage dispersion among workers in the equilibrium. When highskilled workers are more productive and impose a positive externality on low-skilled workers, we find that wage dispersion within and across groups of workers increases. This result opposes to the prediction of Blazquez and Jansen (2008) due to the presence of on-the-job search activity by low-skilled workers in our framework. On another note, low-skilled workers accept significantly lower reservation wages because they expect to find a better paid job at high productivity firms in the future. The bargained wages of high-skilled workers increase due to better outside options. Therefore, the wage dispersion within and across groups of workers is widened. The effect is stronger when the productivity difference of being employed at low and high productivity firms for low-skilled workers increases. When the low-skilled workers are as productive as their first jobs at high productivity firms, these effects are negligible and wage gap among workers is small. Nevertheless, this finding is inline with empirical evidence. The study by Dustmann and Meghir (2005) shows that unskilled workers gain more by changing their jobs, and claims that job mobility is an important source of wage growth in Germany. Another study by Del Bono and Vuri (2011) finds that job mobility explains nearly to $30 \%$ of total log wage growth for men and $8.3 \%$ for women in Italy. Our numerical results suggest that the majority of low-skilled workers are employed at high productivity firms in the equilibrium. Similar to Gautier (2002) and Stupnytska and Zaharieva (2017), low-skilled workers gain from the high productivity of high-skilled workers.

Finally, our numerical results indicate the presence of two types of firms in the equilibrium when endogenous choice of wage setting mechanism is considered. This is in contrast with the findings of Ellingsen and Rosen (2003) which show that all firms choose Nash bargaining in the equilibrium. The co-existence of both wage setting mechanisms in our setup is caused by 
the presence of on-the-job search activity, which decreases the reservation wages of low-skilled workers as mentioned above. It motivates firms to open more vacancies in the low productivity submarket. It also encourages firms to open vacancies in the high productivity submarket because they expect high profits by hiring more experienced low-skilled workers. As a result, both type of firms emerge in the equilibrium in our benchmark economy.

Several empirical studies find frequent use of the take-it-or-leave-it and Nash bargaining wage determination processes. Brenzel et al (2014) empirically study a survey data and show that these two different wage determination mechanisms coexist in the German labour market. The take-it-or-leave-it wage setting accounts for around two-third, and Nash bargaining for around one-third of total hirings. Hall and Krueger (2008) find that wage posting and bilateral bargaining wage are equally frequent in the USA labour market. The wage is determined through the take-it-or-leave-it or the bargaining for around 35\% of workers according to their study. Moreover, the take-it-or-leave-it appears to be more common for lower educated workers, for union members and for government jobs. Whereas, Nash bargaining is more frequent for more educated workers.

There are several empirical studies which establish job-to-job mobility in the labour market. For example, Jolivet et al (2006) estimate a partial equilibrium search model using three-year panel data for individuals covering 10 European countries and the USA. Both job-to-job and jobto-unemployment transition rates vary across countries, though these two transition rates show little cross-country variation. They find that job-to-job transition rates are between $9 \%$ and $15 \%$ in all countries except France (4\%) and Spain (23\%). Nagypal (2008) documents that almost $50 \%$ of all job separations in the USA labour market are explained by job-to-job transitions.

This paper is closely related to the literature on labour markets with heterogeneous workers and firms, and social welfare. Albrecht and Vroman (2002) develop a theoretical model with heterogeneous workers and heterogeneous firms, endogenous skill requirements, but without on-the-job search. The distribution of workers is exogenously given, and all firms rely on Nash bargaining to determine wages. Two types of equilibria emerge depending on parameter settings: cross-skill matching, and ex-post segmentation. In the former case high-skilled workers accept low-skilled jobs because it is beneficial for them to do so, while in the latter case high-skilled workers only take high-skilled jobs. However, in the present model only cross-skill matching equilibrium emerges. Shi (2002) considers a directed search model with heterogeneous workers and heterogeneous firms, again without on-the-job search. Both types of workers are allowed to be employed at high-tech firms while low-skilled workers are employed only at low-tech firms. The search process is directed by firms, and high-tech firms favor to employ high-skilled workers. His model generates a similar pattern of wage inequality, which is consistent with USA labour market of 1970s, 1980s and 1990s. Within group wage gap increases despite the fact that college premium declines for some periods, and the equilibrium is socially optimal due to the directed search mechanism.

Gautier (2002) develops a similar model to Albrecht and Vroman (2002) by introducing onthe-job search. All workers can apply for simple jobs, and high-skilled workers are allowed to seek a complex job while they are employed. While unskilled workers are employed at only simple jobs. He shows that low-skilled workers can benefit from the high productivity level of high-skilled workers which is similar to our findings with baseline parameters. Ellingsen and 
Rosen (2003) consider a search model with heterogeneous workers and endogenous wage policy but without on-the-job search. Firms are allowed to open vacancies in both markets, namely, wage posting and bilateral bargaining depending on workers' types. It is shown that all firms choose Nash bargaining when cost of opening vacancy and separation rates are low, matching efficiency is high, and workers are high productive. In contrast to their results we find that both types of firms emerge in the equilibrium.

Blazquez and Jansen (2008), Albrecht et al (2010), and Stupnytska and Zaharieva (2017) focus on social efficiency. The model by Blazquez and Jansen (2008) is based on the framework of Albrecht and Vroman (2002). The main results are the following: Nash bargaining never leads to an efficient outcome, and the traditional Hosios condition can not fully internalize externalities. Nevertheless, bargaining reduces wage dispersion relative to workers' shadow values. Lower wages of high ability workers make the creation of skilled jobs profitable, while the high wages of low ability workers discourage the creation of unskilled jobs. Albrecht et al (2010) develop a search model with endogenous participation of heterogeneous workers, but without on-thejob search. They show that Hosios condition ${ }^{1}$ restores a socially efficient outcome, but leads to an excessive number of job creations. Stupnytska and Zaharieva (2017) develop a search model with heterogeneous workers and social networks without on-the-job search. Firms decide endogenously to open a vacancy in the regular job market or in the referral market. They show that the decentralized equilibrium is inefficient, although there exist policy instruments that are able to restore efficient outcomes. They assume that high ability workers have large number of social contacts which contributes to the large wage gap between low and high ability workers and to the large difference of the unemployment rates.

It is well documented that apprenticeship programs are intended to fill the shortage of highskilled workers and they are well developed in a number of countries such as Germany, Great Britain and Switzerland (Ryan et al; 2011). The outcome of the program varies across countries, nevertheless apprenticeship system helps to mitigate the risk of being unemployed for long periods and increases the opportunities of young workers to find permanent jobs. For example, Van der Velden et al (2001) find that the countries with apprenticeship systems have better employment outcomes for young workers. As a result a greater share of them employed in the high productivity jobs and receive higher wages compared to the young workers of the countries without any apprenticeship program. Lodovici et al (2013) also report a positive relationship between the incidence rate of apprenticeship and the youth employment rate for European countries. The study by Hoftmann et al (2017) indicates that there is a strong demand for student apprentices, and firms offer various training programs in Germany. However, employers are still facing difficulty to fill positions for apprentices because they offer low wages, so the majority of students prefer to obtain high degree and seek better paid jobs. The proposed model may help to shed light on this phenomenon of German labour market. The low productivity jobs in our framework are similar to apprenticeship positions with respect to wages, because both of them offer low wages.

The paper proceeds as follows. In section 2 we explain the labour market structure. In section 3 we describe the model and derive the value functions for workers and firms at the

\footnotetext{
${ }^{1}$ Mangin and Julien (2018) consider a search model which generalizes Hosios condition. However, such generalized condition only applies to the framework without on-the-job search.
} 
decentralized equilibrium. Section 4 contains welfare analyses and section 5 provides numerical results of the model. Finally, section 6 concludes the paper.

\section{Model}

Time is continuous and workers are risk-neutral. We normalize the population size to 1 . Workers and firms discount the future at rate $r$. Workers can be low or high skilled, and firms can have low or high productivity. Let $\mu$ denote the fraction of low-skilled workers producing the flow output $y_{L}$ when employed, and $(1-\mu)$ be the fraction of high-skilled workers producing the flow output $y_{H}$ when employed. Assume that unemployed low and high skilled workers are restricted to seek jobs at low and high productivity firms, respectively. Employed lowskilled workers are allowed to seek better paid jobs at high productivity firms and they produce the flow output $y_{L H}$, when they are employed at high productivity firms. It is assumed that low-skilled workers are not productive as high-skilled workers when they are employed at high productivity firms. Table 1 summarizes the productivity levels upon different matches. Let $e_{L L}$ and $e_{L H}$ denote the number of low-skilled workers employed at low and high productivity firms, respectively. Moreover, $u_{L}$ and $u_{H}$ denote the fraction of unemployed low and high skilled workers, respectively, and $e_{H}$ the number of employed high-skilled workers. So, the following expressions apply: $u_{L}+e_{L L}+e_{L H}=\mu$ and $u_{H}+e_{H}=(1-\mu)$. The two types of firms use different wage determination mechanisms. Low productivity firms rely on take-it-or-leave-it wage offers, while high productivity firms use Nash bargaining. We consider two possible setups. In the first, which we call exogenous participation, the fractions of two types of firms are exogenously given. In the second, called endogenous participation, these fractions are endogenously determined within the model. Let $\eta$ be the fraction of low productivity firms. Let us denote the flow cost of opening a vacancy for low productivity firms with $c_{L}$, and $c_{H}$ for high productivity firms, with $c_{L}<c_{H}$. We assume that the job destruction rate equals $\delta_{L}$ for low productivity firms and $\delta_{H}$ for high productivity firms, with $\delta_{L}>\delta_{H}$. We denote with $v_{L}$ and $v_{H}$ the number of vacancies for low and high productivity firms, respectively. Finally, we use random matching following Pissarides (1994). The matching function is constant returns to scale, increasing and concave in both arguments; $m_{i}\left(s_{i}, v_{i}\right)=m_{0} s_{i}^{\alpha} v_{i}^{1-\alpha}, i=L, H$. We denote with $s_{L}$ and $s_{H}$ the number of job seekers, $s_{L}=u_{L}$ and $s_{H}=\left(u_{H}+e_{L L}\right)$ for low and high productivity submarkets, respectively. Labour market tightnesses are given by $\theta_{L}=v_{L} / s_{L}$ and $\theta_{H}=v_{H} / s_{H}$. The job finding rates for the two types of firms are $\lambda\left(\theta_{L}\right)=m_{0} \theta_{L}^{1-\alpha}$ and $\lambda\left(\theta_{H}\right)=m_{0} \theta_{H}^{1-\alpha}$, and the corresponding job filling rates are $q\left(\theta_{L}\right)=m_{0} \theta_{L}^{-\alpha}$ and $q\left(\theta_{H}\right)=m_{0} \theta_{H}^{-\alpha}$.

\begin{tabular}{lcc}
\hline & \multicolumn{2}{c}{ Firm type } \\
Worker type & Low productive & High productive \\
(Take-it-or-leave-it) & (Nash bargaining) \\
Low & $y_{L}$ & $y_{L H}$ \\
High & 0 & $y_{H}$ \\
\hline
\end{tabular}

Table 1: Match specific productivities: $y_{L}<y_{L H}<y_{H}$ 


\section{Decentralized Equilibrium}

\subsection{Value functions}

Let $U_{L}$ and $U_{H}$ be the present values of being unemployed for low and high skilled workers, respectively, and $W_{L}(w)$ and $W_{L H}(w)$ be the present values of being employed for low-skilled workers at the current wage $w$ in low and high productivity firms, respectively. Similar, let $W_{H}(w)$ be the present value of being employed for high-skilled workers at the current wage $w$. The structure of the labour market is presented in Figure 1. In addition, let $\tau_{L}$ and $\tau_{H}$ be the flow values of transfers that unemployed workers receive from the public budget, and $T$ be the flow value of transfer that all workers contribute to the budget. The present values $U_{L}$ and $U_{H}$ for unemployed workers are given by

$$
r U_{L}=z+\tau_{L}+\lambda\left(\theta_{L}\right)\left(W_{L}-U_{L}\right)-T \quad r U_{H}=z+\tau_{H}+\lambda\left(\theta_{H}\right)\left(W_{H}-U_{H}\right)-T .
$$

Unemployed workers receive the flow unemployment benefit $z$ and find jobs at rates $\lambda\left(\theta_{i}\right)$, so the expected gain from finding a job becomes: $\lambda\left(\theta_{i}\right)\left(W_{i}-U_{i}\right)$, where $i$ shows the worker's type and it is denoted by $L$ for low-skilled, and $H$ for high-skilled workers. The reservation wages for both types of workers can be determined at wage rates when workers are indifferent between being unemployed and employed: $U_{L}=W_{L}\left(w_{L}^{*}\right)$ and $U_{H}=W_{H}\left(w_{H}^{*}\right)$. This means that unemployed workers accept only wage offers that are higher than their reservation wages.

The present values of being employed at current wage $w$ can be written as

$$
\begin{gathered}
r W_{L}(w)=w+\lambda\left(\theta_{H}\right)\left(W_{L H}\left(w_{L H}\right)-W_{L}(w)\right)-\delta_{L}\left(W_{L}(w)-U_{L}\right)-T, \\
r W_{L H}(w)=w-\delta_{H}\left(W_{L H}(w)-U_{L}\right)-T, \quad r W_{H}(w)=w-\delta_{H}\left(W_{H}(w)-U_{H}\right)-T,
\end{gathered}
$$

where low-skilled workers receive the flow wage $w$ and are allowed to seek better jobs in the high productivity submarket, entailing an expected gain equal to $\lambda\left(\theta_{H}\right)\left(W_{L H}\left(w_{L H}\right)-W_{L}(w)\right)$ in equation (2). Any low and high skilled workers may lose their jobs at rates $\delta_{L}$ and $\delta_{H}$, respectively.

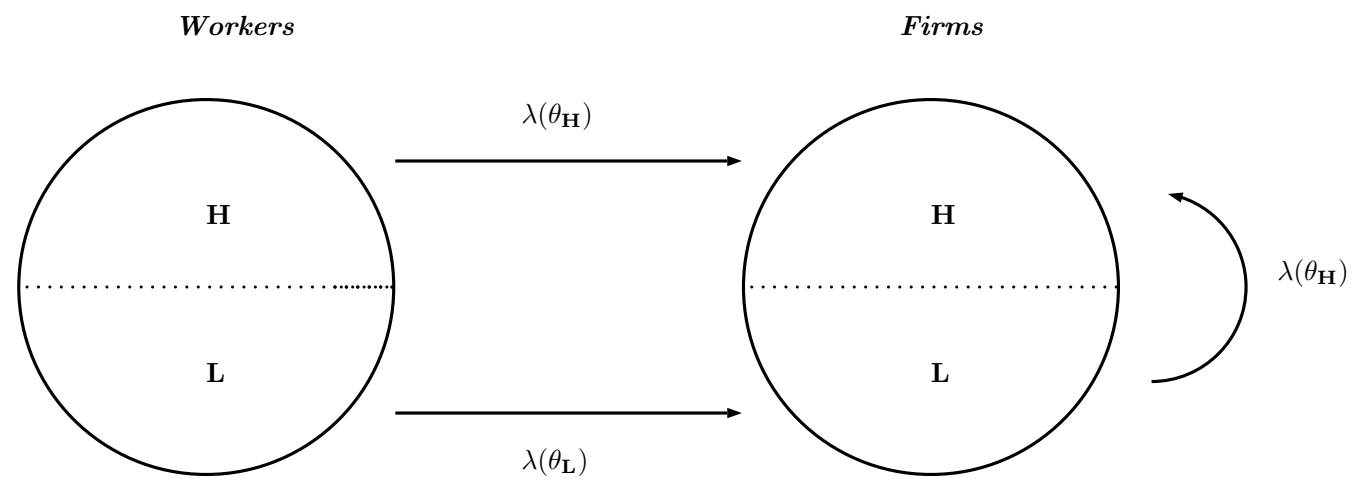

Figure 1: Labour market flows

Let $J_{L}$ denote the present value of filled jobs for low productivity firms. Similar, let $J_{L H}$ and $J_{H}$ be the present values of jobs that are filled by low and high skilled workers at high 
productivity firms. $V$ is the expected present value of open vacancies. Therefore, the Bellman equations for filled jobs can be written as

$$
\begin{gathered}
r J_{L}\left(y_{L}, w\right)=y_{L}-w-\delta_{L}\left(J_{L}\left(y_{L}, w\right)-V\right)-\lambda\left(\theta_{H}\right)\left(J_{L}\left(y_{L}, w\right)-V\right), \\
r J_{L H}\left(y_{L H}, w\right)=y_{L H}-w-\delta_{H}\left(J_{L H}\left(y_{L H}, w\right)-V\right), \\
r J_{H}\left(y_{H}, w\right)=y_{H}-w-\delta_{H}\left(J_{H}\left(y_{H}, w\right)-V\right) .
\end{gathered}
$$

The hiring process of high productivity firms with open vacancies can be described as follows. Both low-skilled employees and unemployed high-skilled workers apply for jobs in high productivity firms. Let $\gamma=u_{H} /\left(u_{H}+e_{L L}\right)$ be the probability of meeting an unemployed high-skilled worker. Thus, $1-\gamma=e_{L L} /\left(u_{H}+e_{L L}\right)$ is the probability of meeting a low-skilled employee. The present values of open vacancies $V_{L}$ and $V_{H}$ for low and high productivity firms are, respectively, given by

$$
r V_{L}=-c_{L}+q\left(\theta_{L}\right)\left(J_{L}\left(y_{L}, w\right)-V\right)
$$

and

$$
r V_{H}=-c_{H}+q\left(\theta_{H}\right)\left[(1-\gamma) J_{L H}\left(y_{L H}, w_{L H}\right)+\gamma J_{H}\left(y_{H}, w_{H}\right)-V\right]
$$

where $w_{L H}$ and $w_{H}$ are the bargained wages for low and high skilled workers, respectively. The term $(1-\gamma) J_{L H}\left(y_{L H}, w_{L H}\right)+\gamma J_{H}\left(y_{H}, w_{H}\right)$ in equation (8) is the expected present value of a filled job for high productivity firms. Furthermore, we assume that the economy is at the steady state, meaning that the difference between net flows into and out of unemployment is stable over time. Thus, the equilibrium unemployment for both types of workers is determined by the following equations

$$
\begin{gathered}
\delta_{L} e_{L L}+\delta_{H} e_{L H}=\lambda\left(\theta_{L}\right) u_{L}, \quad \lambda\left(\theta_{H}\right) e_{L L}=\delta_{H} e_{L H}, \quad \mu=u_{L}+e_{L L}+e_{L H}, \\
\delta_{H}\left(1-\mu-u_{H}\right)=\lambda\left(\theta_{H}\right) u_{H} .
\end{gathered}
$$

These steady-state conditions allow us to express the equilibrium probability of meeting a highskilled worker $\gamma$ as

$$
\gamma \equiv \frac{u_{H}}{\left(u_{H}+e_{L L}\right)}=\frac{(1-\mu) \delta_{H}}{\delta_{H}+\lambda\left(\theta_{H}\right)} /\left[\frac{(1-\mu) \delta_{H}}{\delta_{H}+\lambda\left(\theta_{H}\right)}+\frac{\delta_{H} \lambda\left(\theta_{L}\right) \mu}{\delta_{H}\left(\delta_{L}+\lambda\left(\theta_{H}\right)\right)+\lambda\left(\theta_{L}\right)\left(\delta_{H}+\lambda\left(\theta_{H}\right)\right)}\right],
$$

which implies the following lemma.

Lemma 1: Assume that low-skilled employees and high-skilled workers are seeking jobs at high productivity firms. Then the probability of meeting an unemployed high-skilled worker $\gamma\left(\theta_{L}, \theta_{H}\right)$ 
is decreasing in $\theta_{L}$ and $\theta_{H}$. Moreover, $\lim _{\theta_{L} \rightarrow 0} \gamma\left(\theta_{L}, \theta_{H}\right)=1, \lim _{\theta_{L} \rightarrow \infty} \gamma\left(\theta_{L}, \theta_{H}\right)=(1-\mu)$,

$$
\lim _{\theta_{H} \rightarrow 0} \gamma\left(\theta_{L}, \theta_{H}\right)=\frac{(1-\mu)}{\left[(1-\mu)+\lambda\left(\theta_{L}\right) \mu /\left(\delta_{L}+\lambda\left(\theta_{L}\right)\right)\right]}
$$

and

$$
\lim _{\theta_{H} \rightarrow \infty} \gamma\left(\theta_{L}, \theta_{H}\right)=\frac{(1-\mu)}{\left[(1-\mu)+\lambda\left(\theta_{L}\right) \mu /\left(\delta_{H}+\lambda\left(\theta_{L}\right)\right)\right]}
$$

Proof. See Appendix A.

Intuitively, a higher market tightness $\theta_{L}$ increases the equilibrium employment of low-skilled workers $e_{L L}$, which entails that the probability of a randomly chosen applicant being low-skilled is increasing. Since more low-skilled workers are available the chances of meeting unemployed highskilled workers decrease. Moreover, a higher market tightness $\theta_{H}$ leads to a higher competition among high productivity firms which implies that the probability of filling a job with a highskilled worker decreases.

\subsection{Wage determination and entry conditions}

In this section we focus on the labour market outcomes in the absence of policy instruments $\left(\tau_{L}=\tau_{H}=T=0\right)$. The equilibrium wages are determined by take-it-or-leave-it offers in low productivity firms, and through Nash bargaining in high productivity firms.

Note that it is optimal for low productivity firms to offer the reservation wage $w_{L}^{*}$ to lowskilled workers since unemployed low-skilled workers can only apply to jobs at low productivity firms. This can be easily seen by observing that the value of an open vacancy is decreasing in $w$ for low productivity firms. Indeed, using equations (4) and (7) we can show that

$$
r V_{L}=\frac{-\left(r+\delta_{L}+\lambda\left(\theta_{H}\right)\right) c_{L}+q\left(\theta_{L}\right)\left(y_{L}-w-r V\right)}{\left(r+\delta_{L}+\lambda\left(\theta_{H}\right)\right)}
$$

from which it is clear that the optimal wage is equal to the reservation wage $w_{L}^{*}$, i.e.,

$$
w_{L}^{*}=z-\frac{\lambda\left(\theta_{H}\right) \beta\left(y_{L H}-z-r V\right)}{\left(r+\delta_{H}\right)} .
$$

Turning to high productivity firms, the outside option of a low-skilled employee is earning the wage $w_{L}^{*}$ and she/he maximizes the rent $W_{L H}(w)-W_{L}\left(w_{L}^{*}\right)$ when bargaining over $w$. Similar, when bargaining over $w$ an unemployed high-skilled worker maximizes the rent $W_{H}(w)-U_{H}$ which is an increasing function of $w$. Whereas firms maximize the expected profits $J_{L H}\left(y_{L H}, w\right)-$ $V$ and $J_{H}\left(y_{H}, w\right)-V$. Therefore, the bargained wages $w_{L H}$ and $w_{H}$ must satisfy

$$
w_{L H}=\arg \max \left(W_{L H}(w)-W_{L}\left(w_{L}^{*}\right)\right)^{\beta}\left(J_{L H}\left(y_{L H}, w\right)-V\right)^{1-\beta},
$$

and

$$
w_{H}=\arg \max \left(W_{H}(w)-U_{H}\right)^{\beta}\left(J_{H}\left(y_{H}, w\right)-V\right)^{1-\beta} .
$$


The corresponding bargained wage equations become

$$
w_{L H}=\beta\left(y_{L H}-r V\right)+(1-\beta) r U_{L} \quad \text { and } \quad w_{H}=\beta\left(y_{H}-r V\right)+(1-\beta) r U_{H},
$$

where $r U_{L}=z$ and $r U_{H}=w_{H}^{*}$. Furthermore, we can express the reservation wage $w_{H}^{*}$ as a linear combination of unemployment $z$ and $\left(y_{H}-r V\right)$ by evaluating the second expression in equation (3) at $w_{H}^{*}$ as follows

$$
w_{H}^{*}=\frac{z\left(r+\delta_{H}\right)+\lambda\left(\theta_{H}\right) \beta\left(y_{H}-r V\right)}{\left(r+\delta_{H}+\beta \lambda\left(\theta_{H}\right)\right)} .
$$

Proof. See Appendix A.

Let $S_{L} \equiv J_{L}-V_{L}+W_{L}-\left.U_{L}\right|_{w=w_{L}^{*}}$ be the total job surplus in a match between a low productivity firm and a low-skilled worker. Using the expression for $w_{L}^{*}, S_{L}$ can be expressed as

$$
S_{L}=\frac{\left(y_{L}-z-r V\right)\left(r+\delta_{H}\right)+\lambda\left(\theta_{H}\right) \beta\left(y_{L H}-z-r V\right)}{\left(r+\delta_{H}\right)\left(r+\delta_{L}+\lambda\left(\theta_{H}\right)\right)} .
$$

Let $S_{L H} \equiv J_{L H}-V_{H}+W_{L H}-\left.U_{L}\right|_{w=w_{L H}}$ and $S_{H} \equiv J_{H}-V_{H}+W_{H}-\left.U_{H}\right|_{w=w_{H}}$ be the total job surplus in a match between a high productivity firm and a low-skilled employee, and between a high productivity firm and a high-skilled worker, respectively. The surplus values $S_{L H}$ and $S_{H}$ can be written as

$$
S_{L H}=\frac{\left(y_{L H}-z-r V\right)}{\left(r+\delta_{H}\right)}, \quad S_{H}=\frac{\left(y_{H}-z-r V\right)}{\left(r+\delta_{H}+\beta \lambda\left(\theta_{H}\right)\right)} .
$$

Note that the total surplus $S_{H}$ can be higher or lower than $S_{L H}$ depending on the productivity difference $\left(y_{H}-y_{L H}\right)$ and the equilibrium market tightness $\theta_{H}$.

Next, we discuss the entry conditions for the firms in the model. Denote with $K$ entry cost paid by each firm, and with $v$ the total number of vacancies created by both types of firms. After entering the market, firms learn their own types: with probability $\eta$ the firm is of low productivity and uses take-it-or-leave-it wage offers, while with probability $(1-\eta)$ it is of high productivity and rely on Nash bargaining to determine wages. Thus, the number of vacancies for low and high productivity firms become $v_{L}=\eta v$ and $v_{H}=(1-\eta) v$, respectively. We consider two possible scenarios depending on whether the shares of the two types of firms is exogenously given or endogenously determined. First, we specify exogenously the fraction of low and high productivity firms. In order to determine $v$ we can write

$$
V=\eta V_{L}+(1-\eta) V_{H} \quad \text { and } V=K
$$

indicating that firms continue entering the market as long as the present value of open vacancies $V$ is higher or equal than the entry cost $K$. Note that $V_{L}<V<V_{H}$ holds by the assumption and the optimal strategy by firms is $V$ when they open vacancies. Second, we allow firms to choose their wage setting mechanism endogenously. Firms are allowed to open vacancies for the low or high productivity submarket. Indifference between opening a vacancy in either low or 
high productivity submarket implies that

$$
V_{L}=V_{H}=V=K
$$

Note that this condition satisfies equation (13) as well. We discuss how the decentralized equilibrium levels of vacancies are determined in each scenario in the following subsections.

\subsection{Exogenous participation}

We analyze the decentralized equilibrium when the share of the two types of firms is exogenously given. Denote with $J C_{L}$ and $J C_{H}$ the job creation curves for low and high productivity submarkets, respectively. The entry condition in each of the two submarkets is given by

$$
\frac{\left(c_{L}+r V_{L}\right)}{q\left(\theta_{L}\right)}=S_{L} \quad\left(J C_{L}\right)
$$

and

$$
\frac{\left(c_{H}+r V_{H}\right)}{q\left(\theta_{H}\right)}=(1-\beta)\left[\left(1-\gamma\left(\theta_{L}, \theta_{H}\right)\right) S_{L H}+\gamma\left(\theta_{L}, \theta_{H}\right) S_{H}\right] . \quad\left(J C_{H}\right)
$$

Two job creation curves imply that the expected cost of an open vacancy in the equilibrium should be equal to the expected profit of a filled job. The left hand-side of the entry condition corresponds to the expected cost of an open vacancy and the right hand-side is the expected profit of a filed job. In addition, since unemployed low-skilled workers do not have bargaining power, low productivity firms capture the total job surplus $S_{L}$ as profit. While Nash bargaining implies that high productivity firms obtain a fraction $(1-\beta)$ of the expected total job surplus $\left[\left(1-\gamma\left(\theta_{L}, \theta_{H}\right)\right) S_{L H}+\gamma\left(\theta_{L}, \theta_{H}\right) S_{H}\right]$ as profits.

Definition 1. Let the fraction of two types of firms is exogenously given. Then a search equilibrium with heterogeneous workers and firms in the exogenous participation by firms is a vector $\left\{U_{i}, W_{i}, W_{L H}, V_{i}, J_{i}, w_{i}^{*}, w_{L H}, w_{H}, \theta_{i}, u_{i}, e_{L L}, e_{L H}, e_{H}, v_{i}\right\}$, for $i=L, H$, satisfying, the Bellman equations (1)-(3) for workers, the equations (4)-(8) for firms, the equilibrium conditions (11) and (12) for wages, the entry condition (13), as well as the steady state conditions (9) and (10) for workers.

Proposition 1. Let the fraction of two types of firms is exogenously given. Assume that $y_{i} \geq(z+r K)$ for $i=L, L H, H$, and the economy is at steady state. Then the total number of vacancies $v$ is determined by:

$\eta\left[q\left(\theta_{L}\right) S_{L}-\left(c_{L}+r K\right)\right]+(1-\eta)\left[(1-\beta)\left(q\left(\theta_{H}\right)(1-\gamma) S_{L H}+q\left(\theta_{H}\right) \gamma S_{H}\right)-\left(c_{H}+r K\right)\right]=0$

Proof. See Appendix B.

If we consider an economy in which workers have bargaining power $\beta$ at low productivity submarket and there is no on-the-job search activity by these workers, the job creation curves can be written as:

$$
\left(c_{L}+r V_{L}\right)=(1-\beta) q\left(\theta_{L}\right) S_{L}
$$




$$
\left(c_{H}+r V_{H}\right)=(1-\beta) q\left(\theta_{H}\right) S_{H}
$$

where we use the fact that high productivity jobs are only filled with high-skilled workers, i.e., $\gamma=1$ and no on-the-job search by low-skilled workers, i.e., $\lambda\left(\theta_{H}\right)=0$. Further, in the decentralized equilibrium the total number of vacancies $v$ is determined by:

$$
\eta\left[q\left(\theta_{L}\right)(1-\beta) S_{L}-\left(c_{L}+r K\right)\right]+(1-\eta)\left[q\left(\theta_{H}\right)(1-\beta) S_{H}-\left(c_{H}+r K\right)\right]=0,
$$

where $S_{L}=\frac{\left(y_{L}-z-r K\right)}{\left(r+\delta_{L}+\beta \lambda\left(\theta_{L}\right)\right)}$ and $S_{H}=\frac{\left(y_{H}-z-r K\right)}{\left(r+\delta_{H}+\beta \lambda\left(\theta_{H}\right)\right)}$, and noting that $\eta\left(V_{L}-K\right)+(1-\eta)\left(V_{H}-K\right)=$ 0 . Therefore, proposition 1 reveals that the equilibrium vacancies are created by taking into account the additional two factors that low-skilled workers do not have bargaining power at low productivity submarket and on-the-job search activity by these workers. This proposition is an extended version of the standard case.

\subsection{Endogenous participation}

Next, we consider the endogenous choice of the wage setting mechanism and firms are allowed to open vacancies in both submarkets. In this case, the entry condition is only different and it is determined by indifference between opening a vacancy in either low or high productivity submarket. The remaining main equations in the model are kept as the same as the previous section.

Definition 2. A search equilibrium with heterogeneous workers and firms in the endogenous participation by firms is a vector $\left\{U_{i}, W_{i}, W_{L H}, V_{i}, J_{i}, w_{i}^{*}, w_{L H}, w_{H}, \theta_{i}, u_{i}, e_{L L}, e_{L H}, e_{H}, v_{i}\right\}$, for $i=L, H$, satisfying, the Bellman equations (1)-(3) for workers, the equations (4)-(8) for firms, the equilibrium conditions (11) and (12) for wages, the entry condition (14), as well as the steady state conditions (9) and (10) for workers.

Proposition 2. Let the wage setting mechanism be endogenously chosen by firms. Assume that $y_{i} \geq(z+r K)$ for $i=L, L H, H$. Then there exists a search equilibrium such that the market tightnesses $\theta_{L}$ and $\theta_{H}$ are determined through the two job creation conditions

$$
\begin{gathered}
\frac{\left(c_{L}+r K\right)}{q\left(\theta_{L}\right)}=\frac{\left(y_{L}-z-r K\right)\left(r+\delta_{H}\right)+\beta \lambda\left(\theta_{H}\right)\left(y_{L H}-z-r K\right)}{\left(r+\delta_{H}\right)\left(r+\delta_{L}+\lambda\left(\theta_{H}\right)\right)}, \quad\left(J C_{L}\right) \\
\frac{\left(c_{H}+r K\right)}{q\left(\theta_{H}\right)}=(1-\beta)\left[\frac{\left(1-\gamma\left(\theta_{L}, \theta_{H}\right)\right)\left(y_{L H}-z-r K\right)}{\left(r+\delta_{H}\right)}+\frac{\gamma\left(\theta_{L}, \theta_{H}\right)\left(y_{H}-z-r K\right)}{\left(r+\delta_{H}+\beta \lambda\left(\theta_{H}\right)\right)}\right] . \quad\left(J C_{H}\right)
\end{gathered}
$$

Proof. See Appendix B.

Proposition 2 implies that the equilibrium market tightnesses $\theta_{L}$ and $\theta_{H}$ are determined by the two curves $\left(J C_{L}\right)$ and $\left(J C_{H}\right)$. Note that $\left(J C_{L}\right)$ implies a positive (negative) relationship between $\theta_{L}$ and $\theta_{H}$ when the productivity level $y_{L}$ is below (above) threshold $y_{L}^{*}=z+r K+$ $\beta\left(y_{L H}-z-r K\right)\left(r+\delta_{L}\right) /\left(r+\delta_{H}\right)$. In addition, $\theta_{L}$ asymptotically converges to the upper (lower) bound $\overline{\theta_{L}}\left(\underline{\theta_{L}}\right)$ which is the solution of $\left(c_{L}+r K\right) / q\left(\theta_{L}\right)=\lim _{\theta_{H} \rightarrow \infty} S_{L}$ when the productivity level $y_{L}$ is below (above) the threshold $y_{L}^{*}$. Figure 2 describes this idea. Intuitively, when the productivity difference $\left(y_{L H}-y_{L}\right)$ is large, high productivity firms have incentive to open 


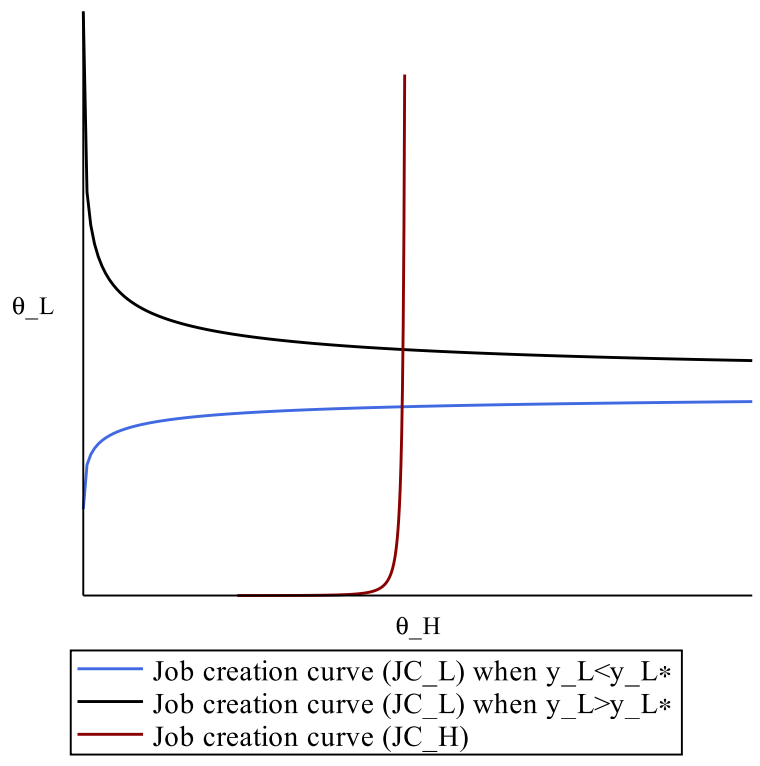

Figure 2: $J C_{L}$ and $J C_{H}$ curves

more vacancies. Thus, firms are willing to hire more low-skilled employees, stimulating the creation of more vacancies in the low productivity submarket. In this scenario, the reservation wage $w_{L}^{*}$ for low-skilled workers decreases significantly as workers expect to find better jobs at high productivity firms in the future. Conversely, when the productivity difference $\left(y_{L H}-y_{L}\right)$ is small, finding jobs at high productivity firms is not as attractive for low-skilled workers to accept significantly lower reservation wages. Opening a vacancy in the high productivity submarket creates rather a competition effect. Thus, it is not profitable for low productivity firms to create vacancies, implying that the relationship between $\theta_{L}$ and $\theta_{H}$ becomes negative.

Further, under our parameter settings, $\left(J C_{H}\right)$ implies a positive relationship between equilibrium market tightnesses $\theta_{L}$ and $\theta_{H}$. Then the curve $\left(J C_{H}\right)$ implies lower and upper bounds for $\theta_{H}$ as well. These results are summarized in corollary 1.

Corollary 1: The curves $\left(J C_{L}\right)$ and $\left(J C_{H}\right)$ imply lower and upper bounds for market tightness variables under the following cases

Case 1: Let $\left(J C_{L}\right)$ curve implies a positive relationship between $\theta_{L}$ and $\theta_{H}$. Then lower $\theta_{L}$ and upper $\overline{\theta_{L}}$ bounds for $\theta_{L}$ are determined, respectively, by

$$
\frac{\left(c_{L}+r K\right)}{q\left(\theta_{L}\right)}=\frac{\left(y_{L}-z-r K\right)}{\left(r+\delta_{L}\right)} \quad \text { and } \quad \frac{\left(c_{L}+r K\right)}{q\left(\theta_{L}\right)}=\frac{\beta\left(y_{L H}-z-r K\right)}{\left(r+\delta_{H}\right)}
$$

Case 2: Let $\left(J C_{L}\right)$ curve implies a negative relationship between $\theta_{L}$ and $\theta_{H}$. Then lower and upper bounds for $\theta_{L}$ are reversed and determined by

$$
\frac{\left(c_{L}+r K\right)}{q\left(\theta_{L}\right)}=\frac{\beta\left(y_{L H}-z-r K\right)}{\left(r+\delta_{H}\right)} \quad \text { and } \quad \frac{\left(c_{L}+r K\right)}{q\left(\theta_{L}\right)}=\frac{\left(y_{L}-z-r K\right)}{\left(r+\delta_{L}\right)}
$$

The $\left(J C_{H}\right)$ curve implies lower $\underline{\theta_{H}}$ and upper $\overline{\theta_{H}}$ bounds for $\theta_{H}$ are determined, respectively, by

$$
\frac{\left(c_{H}+r K\right)}{q\left(\theta_{H}\right)}=(1-\beta) \frac{\left(y_{H}-z-r K\right)}{\left(r+\delta_{H}+\beta \lambda\left(\theta_{H}\right)\right)}
$$


and

$$
\frac{\left(c_{H}+r K\right)}{q\left(\theta_{H}\right)}=(1-\beta)\left[\frac{\mu\left(y_{L H}-z-r K\right)}{\left(r+\delta_{H}\right)}+\frac{(1-\mu)\left(y_{H}-z-r K\right)}{\left(r+\delta_{H}+\beta \lambda\left(\theta_{H}\right)\right)}\right]
$$

Proof. See Appendix B.

Our model always exhibits a cross-skill matching equilibrium and absence of ex-post segmentation equilibrium. In addition, in our setup the equilibrium depends on aggregate market tightnesses. These results differ from those obtained by Albrecht and Vroman (2002), who find the possibility of existence of two equilibria depending on the choice of parameters, and obtain that the cross-skill matching equilibrium does not depend on aggregate market tightness. It is important to note that our results are driven by on-the-job search which is not considered by Albrecht and Vroman (2002). Indeed, our findings are consistent with those obtained by Dolado et al (2008), who extend the model by introducing on-the-job search. The following lemma summarizes the relationship between the wages of low and high skilled workers.

Lemma 2: The bargained wages $w_{H}$ of high-skilled workers are larger than the bargained wages $w_{L H}$ of low-skilled workers, i.e., $w_{H}>w_{L H}$. Moreover, for both low and high skilled workers the bargained wage is greater than the reservation wage, i.e., $w_{L H}>w_{L}^{*}$ and $w_{H}>w_{H}^{*}$.

Proof. See Appendix B.

Lemma 2 implies that the wage dispersion both within the group of low-skilled workers, i.e. $\Delta w_{L} \equiv w_{L H}-w_{L}^{*}=\frac{\beta\left(y_{L H}-z-r K\right)\left(r+\delta_{H}+\lambda\left(\theta_{H}\right)\right)}{\left(r+\delta_{H}\right)}$, and across the groups of workers, i.e. $\Delta w_{H} \equiv$ $w_{H}-w_{L H}=\beta\left(y_{H}-y_{L H}\right)+\frac{(1-\beta) \lambda\left(\theta_{H}\right) \beta\left(y_{H}-z-r K\right)}{\left(r+\delta_{H}+\beta \lambda\left(\theta_{H}\right)\right)}$, are increasing in $\theta_{H}$. Intuitively, on the one hand, increase in the opportunities of finding better paid jobs for low-skilled workers reduces their reservation wages. On the other hand, higher market tightness improves the outside options of high-skilled workers and increases their bargained wages. Therefore, the wage dispersion within and across the group of workers increases.

\section{Social Optimum}

This section analyzes the efficiency properties of the decentralized equilibrium both when the share of the two types of firms is assumed to be exogenous and when it is endogenous.

\subsection{Exogenous participation}

We focus on the social planner problem under the assumption that the share of the two types of firms is exogenously given. Welfare function is defined as the present discounted value of output minus the costs of job creation. So that the social planner solves the following problem:

$$
\begin{array}{r}
\max _{\left\{v, u_{L}, u_{H}, e_{L H}\right\}} \int_{0}^{\infty} e^{-r t}\left[z\left(u_{L}+u_{H}\right)+e_{L L}\left(y_{L}-r K\right)+e_{L H}\left(y_{L H}-r K\right)+e_{H}\left(y_{H}-r K\right)\right. \\
\left.-\theta_{L} u_{L}\left(c_{L}+r K\right)-\theta_{H}\left(u_{H}+e_{L L}\right)\left(c_{H}+r K\right)\right] d t
\end{array}
$$

subject to the steady-state equations, and the dynamics of employment and unemployment: $\mu=$ $u_{L}+e_{L L}+e_{L H}, \quad 1-\mu=u_{H}+e_{H}, \quad e_{\dot{L} H}=\lambda\left(\theta_{H}\right) e_{L L}-\delta_{H} e_{L H}, \quad \dot{u}_{L}=\delta_{L} e_{L L}+\delta_{H} e_{L H}-\lambda\left(\theta_{L}\right) u_{L}$, and $u_{H}=\delta_{H} e_{H}-\lambda\left(\theta_{H}\right) u_{H}$. The following proposition provides the optimal solution in the steady 
state.

Proposition 3. Consider a social planner choosing the total number of vacancies $v$, the unemployment rates $u_{L}$ and $u_{H}$ for both submarkets, and the fraction $e_{L H}$ of low-skilled workers employed by high productivity firms. Then the optimal job creation is given by

$$
\begin{aligned}
\eta\left[(1-\alpha) q\left(\theta_{L}\right) \phi_{u_{L}}-\left(c_{L}+r K\right)\right]+(1-\eta)\left[(1-\alpha) q\left(\theta_{H}\right) \gamma \phi_{u_{H}}+\right. & \\
& \left.+(1-\alpha) q\left(\theta_{H}\right)(1-\gamma) \phi_{e_{L H}}-\left(c_{H}+r K\right)\right]=0,
\end{aligned}
$$

where the costate variables $\phi_{u_{L}}, \phi_{u_{H}}$ and $\phi_{e_{L H}}$ are obtained as

$$
\begin{gathered}
\phi_{u_{L}}=\frac{\left(y_{L}-z-r K\right)-\theta_{H}\left(c_{H}+r K\right)+\phi_{e_{L H}} \lambda\left(\theta_{H}\right)}{\left(r+\delta_{L}+\alpha \lambda\left(\theta_{L}\right)\right)}, \\
\phi_{u_{H}}=\frac{y_{H}-z-r K+(1-\alpha) \lambda\left(\theta_{H}\right)(1-\gamma) \phi_{e_{L H}}}{\left(r+\delta_{H}+\alpha \lambda\left(\theta_{H}\right)\right)}, \\
\phi_{e_{L H}}=\frac{\left(y_{L H}-y_{L}\right)+\left(\delta_{L}-\delta_{H}\right) \phi_{u_{L}}+(1-\alpha) \gamma \lambda\left(\theta_{H}\right) \phi_{u_{H}}}{\left(r+\delta_{H}+\lambda\left(\theta_{H}\right)-(1-(1-\gamma)(1-\alpha)) \lambda\left(\theta_{H}\right)\right)} .
\end{gathered}
$$

Proof. See Appendix C.

The first equation of this proposition shows that the socially optimal total number of vacancies $v$ is obtained when the total net profit equals to the total cost of job creation. The costate variables $\phi_{u_{L}}$ and $\phi_{u_{H}}$ are shadow prices (marginal gains) associated with a unit decrease in the unemployment levels $u_{L}$ and $u_{H}$, respectively. Similar, $\phi_{e_{L H}}$ is the marginal gain associated with a unit increase in the employment level $e_{L H}$. For example, the nominator of the expression for $\phi_{u_{L}}$ is the net benefit from hiring a low-skilled worker. The denominator consists of discount factors: job finding rate $\lambda\left(\theta_{L}\right)$, job destruction rate $\delta_{L}$ and interest rate $r$.

The first expression in square brackets in the nominator of $\phi_{u_{L}}$ is the benefit for the unemployed low-skilled worker when employed at a low productivity firm. When employed, low-skilled employee is generating output of $\left(y_{L}-z-r K\right)$, and minus the job creation cost $\theta_{H}\left(c_{H}+r K\right)$. The last expression in the square brackets $\lambda\left(\theta_{H}\right) \phi_{e_{L H}}$ is the expected gain of experienced lowskilled employees when they find better opportunities and get new jobs at high productivity firms.

Further, we can compare the first equation of proposition 3 to one obtained in proposition 1. This implies that the decentralized equilibrium is not constraint efficient even if the Hosios condition holds. To be more precise, let us consider the standard case one without on-the-job search and all workers have bargaining power. Then the socially optimal level of vacancies $v$ is determined by:

$$
\eta\left[q\left(\theta_{L}\right)(1-\beta) \phi_{u_{L}}-\left(c_{L}+r K\right)\right]+(1-\eta)\left[q\left(\theta_{H}\right)(1-\beta) \phi_{u_{H}}-\left(c_{H}+r K\right)\right]=0,
$$

where $\phi_{u_{L}}=\frac{\left(y_{L}-z-r K\right)}{\left(r+\delta_{L}+\alpha \lambda\left(\theta_{L}\right)\right)}$ and $\phi_{u_{H}}=\frac{\left(y_{H}-z-r K\right)}{\left(r+\delta_{H}+\alpha \lambda\left(\theta_{H}\right)\right)}$. Hence, in the standard case the decentral- 
ized equilibrium is constraint efficient when the Hosios condition holds $(\beta=\alpha)$ since $S_{L}=\phi_{u_{L}}$ and $S_{H}=\phi_{u_{H}}$ hold by recalling the results in section 3.3 .

\subsection{Endogenous participation}

Next, we consider the social planner problem under the endogenous choice of the wage setting mechanism. Firms are allowed to open vacancies either for the low or the high productivity submarket. The social planner then solves the following problem:

$$
\begin{array}{r}
\max _{\left\{\theta_{L}, \theta_{H}, u_{L}, u_{H}, e_{L H}\right\}} \int_{0}^{\infty} e^{-r t}\left[z\left(u_{L}+u_{H}\right)+e_{L L}\left(y_{L}-r K\right)+e_{L H}\left(y_{L H}-r K\right)+e_{H}\left(y_{H}-r K\right)-\right. \\
\left.-\theta_{L} u_{L}\left(c_{L}+r K\right)-\theta_{H}\left(u_{H}+e_{L L}\right)\left(c_{H}+r K\right)\right] d t(15)
\end{array}
$$

subject to the steady-state equations, and the dynamics of employment and unemployment: $\mu=$ $u_{L}+e_{L L}+e_{L H}, \quad 1-\mu=u_{H}+e_{H}, \quad e_{\dot{L} H}=\lambda\left(\theta_{H}\right) e_{L L}-\delta_{H} e_{L H}, \quad \dot{u}_{L}=\delta_{L} e_{L L}+\delta_{H} e_{L H}-\lambda\left(\theta_{L}\right) u_{L}$, and $\dot{u_{H}}=\delta_{H} e_{H}-\lambda\left(\theta_{H}\right) u_{H}$. The following proposition provides the optimal solution for this problem in the steady state.

Proposition 4. Consider a social planner choosing the market tightnesses $\theta_{L}$ and $\theta_{H}$, unemployment rates $u_{L}$ and $u_{H}$ for both submarkets, and the fraction of $e_{L H}$ low-skilled workers employed by high productivity firms. Then the optimal job creation is given by

$$
\frac{\left(c_{L}+r K\right)}{q\left(\theta_{L}\right)}=(1-\alpha) \phi_{u_{L}} \quad \text { and } \quad \frac{\left(c_{H}+r K\right)}{q\left(\theta_{H}\right)}=(1-\alpha)\left[(1-\gamma) \phi_{e_{L H}}+\gamma \phi_{u_{H}}\right]
$$

where the costate variables $\phi_{u_{L}}, \phi_{u_{H}}$ and $\phi_{e_{L H}}\left(\Delta \phi=\phi_{u_{H}}-\phi_{e_{L H}}\right)$ are obtained as

$$
\begin{gathered}
\phi_{u_{L}}=\frac{y_{L}-z-r K-\lambda\left(\theta_{H}\right)(1-\alpha) \gamma \Delta \phi+\alpha \lambda\left(\theta_{H}\right) \phi_{e_{L H}}}{\left(r+\delta_{L}+\alpha \lambda\left(\theta_{L}\right)\right)}, \\
\phi_{u_{H}}=\frac{y_{H}-z-r K-(1-\alpha) \lambda\left(\theta_{H}\right)(1-\gamma) \Delta \phi}{\left(r+\delta_{H}+\alpha \lambda\left(\theta_{H}\right)\right)}, \phi_{e_{L H}}=\frac{y_{L H}-y_{L}+(1-\alpha) \lambda\left(\theta_{H}\right) \gamma \Delta \phi+\phi_{u_{L}}\left(\delta_{L}-\delta_{H}\right)}{\left(r+\delta_{H}+\alpha \lambda\left(\theta_{H}\right)\right)} .
\end{gathered}
$$

Proof. See Appendix C.

Comparison of $\phi_{u_{L}}$ with $S_{L}$ and $\phi_{e_{L H}}$ with $S_{L H}$ for low-skilled workers and $\phi_{u_{H}}$ with $S_{H}$ for high-skilled workers reveals that the decentralized equilibrium is not constraint efficient, because $S_{L} \neq(1-\alpha) \phi_{u_{L}}$ and $(1-\gamma) S_{L H}+\gamma S_{H} \neq(1-\gamma) \phi_{e_{L H}}+\gamma \phi_{u_{H}}$ even if the traditional Hosios condition $\beta=\alpha$ holds. The first reason for inefficiency is that low-skilled workers do not have any bargaining power when they are employed at low productivity firms. The second reason is that both types of workers are pooled in the same submarket due to presence of on-the-job search. Low-skilled workers are allowed to seek better paid jobs at high productivity firms which creates a congestion externalities in the high productivity submarket. To understand these reasons of inefficiency, let us first consider the labour market with heterogeneous firms but without on-the-job search. Then the equilibrium total job surpluses for the decentralized and 
the centralized economy are given by

$$
S_{L}=\frac{\left(y_{L}-z-r K\right)}{\left(r+\delta_{L}\right)}, \quad \phi_{u_{L}}=\frac{\left(y_{L}-z-r K\right)}{\left(r+\delta_{L}+\alpha \lambda\left(\theta_{H}\right)\right)}
$$

and

$$
S_{H}=\frac{\left(y_{H}-z-r K\right)}{\left(r+\delta_{H}+\beta \lambda\left(\theta_{H}\right)\right)}, \quad \phi_{u_{H}}=\frac{\left(y_{H}-z-r K\right)}{\left(r+\delta_{H}+\alpha \lambda\left(\theta_{H}\right)\right)},
$$

which implies that the decentralized equilibrium is constraint inefficient even in the absence of on-the-job search. Note that to obtain the two expressions above, we use the fact that high productivity jobs are only filled with high-skilled workers, i.e., $\gamma=1$. Consider now an economy in which all workers have bargaining powers and there is no on-the-job search. In this scenario, for the traditional Hosios value of the bargaining power $(\beta=\alpha)$, the following expressions hold $(1-\beta) S_{L}=(1-\alpha) \phi_{u_{L}}=(1-\beta) \frac{\left(y_{L}-z-r K\right)}{\left(r+\delta_{L}+\beta \lambda\left(\theta_{L}\right)\right)}$ and $S_{H}=\phi_{u_{H}}=\frac{\left(y_{H}-z-r K\right)}{\left(r+\delta_{H}+\beta \lambda\left(\theta_{H}\right)\right)}$. Meaning that the externality is neutralized and the market tightness coincides with the optimal choice of the social planner. This allows us to conclude that the inefficiency stems from take-it-or-leave-it wage setting mechanism for low productivity firms and the fact that different types of workers are pooled in the high productivity submarket. ${ }^{2}$ In a general framework with heterogeneous workers, firms and on-the-job search, external effects are not internalized and the equilibrium outcomes are constraint inefficient. Thus, there is the need for redistribution policy to restore efficient outcomes. Proposition 5 characterizes the optimal redistribution policy.

Proposition 5. Let $\beta=\alpha$. There exists a policy scheme $\left\{\tau_{L}, \tau_{H}, T\right\}$ that can restore the socially optimal allocation, where

$$
\tau_{L}=\frac{\left(r+\delta_{H}\right)\left(r+\delta_{L}+\lambda\left(\theta_{H}\right)\right)}{\left(r+\delta_{H}+\beta \lambda\left(\theta_{H}\right)\right)}\left(S_{L}-(1-\beta) \phi_{u_{L}}\right)
$$

and

$$
\begin{array}{r}
\tau_{H}=\frac{\left(r+\delta_{H}+\beta \lambda\left(\theta_{H}\right)\right)}{\gamma}\left[(1-\gamma) S_{L H}+\gamma S_{H}-(1-\gamma) \phi_{e_{L H}}-\gamma \phi_{u_{H}}\right] \\
-\frac{(1-\gamma)}{\gamma}\left(r+\delta_{L}+\lambda\left(\theta_{H}\right)\right)\left(S_{L}-(1-\beta) \phi_{u_{L}}\right),
\end{array}
$$

with endogeneous variables $\gamma, S_{L}, S_{L H}, S_{H}, \phi_{u_{L}}, \phi_{e_{L H}}, \phi_{u_{H}}$ and $\lambda\left(\theta_{i}\right)(i=L, H)$ being evaluated at the socially optimal allocation characterized in proposition 4. Moreover, the transfer $T$ is such that the budget is balanced: $u_{L} \tau_{L}+u_{H} \tau_{H}=T$.

Proof. See Appendix C.

There are three sources of inefficiency in our model. The first stems from a classical search externality in both markets and it is neutralized under the Hosios condition $\beta=\alpha$. The second stems from the fact that low-skilled workers do not have bargaining power at their initial jobs. We can observe that the optimal job creation is obtained at the point where a fraction of total

\footnotetext{
${ }^{2}$ One may want to consider on-the-job search model with only Nash bargaining, but this case turns out to be analytically intractable under rational expectation. However, it is possible to obtain analytically value functions of workers by deviating from rational expectation and when agents are bounded rational as shown in Damdinsuren and Zaharieva (2018).
} 
surplus of the job $(1-\alpha) \phi_{u_{L}}$ equals the cost $\left(c_{L}+r K\right) / q\left(\theta_{L}\right)$. While, in the decentralized equilibrium firms capture the total surplus $S_{L}$, entailing that optimal job creation is distorted. The third source of inefficiency stems from the fact that different types of workers are pooled in the high productivity submarket which is called pooling inefficiency. This type of inefficiency is present in the models by Gautier (2002) and Stupnytska and Zaharieva (2017) as well.

Proposition 5 describes a system of policy instruments that can restore the socially optimal allocation. When $\Delta \phi=\phi_{u_{H}}-\phi_{e_{L H}}<0$, low-skilled workers create a higher job surplus than high-skilled workers, as they expect to be able to find better jobs in the future. Therefore they are more willing to accept their first jobs, which reduces their reservation wages. Therefore, if $\Delta \phi<0$, every additional low-skilled worker searching in the high productivity market increases firms' expected profits, implying low-skilled workers impose a positive externality on high-skilled workers. Hence the optimal policy favors a subsidy $\tau_{L}>0$ for low-skilled workers, aimed at increasing their reservation wages. In a similar way, high-skilled workers create a negative externality on low-skilled workers, which can be mitigated by making it less attractive to find jobs for high-skilled workers.

So the policy instrument $\tau_{H}$ should be modified to decrease workers' rent $\left(W_{H}\left(w_{H}\right)-U_{H}\right)$ for high-skilled workers and to achieve lower expected profits for high productivity firms. The sign of $\tau_{H}$ is ambiguous. This finding is different from the one obtained by Blazquez and Jansen (2008), and Stupnytska and Zaharieva (2017), where authors emphasize that the optimal policy implies a positive value of $\tau_{L}$ and a negative value of $\tau_{H}$. The reason being is that there is a stimulating effect which is due to on-the-job search activity by low-ability workers in our setup while it is absent in both studies. However, in the former it is not required to have employment tax instruments for restoring socially optimal allocation which is similar to our case, while in the latter it is needed only for high productivity firms.

For $\Delta \phi=\phi_{u_{H}}-\phi_{e_{L H}}>0$, the external effects are reversed. In this case, high-skilled workers generate a higher surplus than low-skilled workers. Every additional high-skilled worker in the high productivity submarket increases the expected profits of firms, and so high-skilled workers impose a positive externality on low-skilled workers. Hence, $\tau_{H}$ should be modified making it more attractive to find jobs for high-skilled workers. These transfers are supposed to achieve higher rents for high-skilled workers. In a similar way, low-skilled workers impose a negative externality on high-skilled workers. Therefore, this externality can be mitigated by making it less attractive to find jobs in the high productivity submarket for low-skilled workers. The optimal policy may still favors a positive value of $\tau_{L}>0$ for low-skilled workers, increasing their reservation wages.

\section{Numerical results}

This section provides a numerical analysis of the model discussed in above. We normalize the productivity parameter $y_{L}$ for low productivity firms to 1.25 . The productivity $y_{H}$ for high productivity firms is taken to be 1.45 which is close to the value of Stupnytska and Zaharieva (2017). We choose the productivity $y_{L H}$ equals to 1.35 which is in the middle range of $y_{L}$ and $y_{H}$. These parameters guarantee that $y_{i} \geq(z+r K), i=L, L H, H$. We assume a unit period of time to be one quarter and set the discount rate to $r=0.012$ which corresponds to an annual 
discount rate of $5 \%$. Following Masui (2011), low productivity jobs are assumed to be less stable than high productivity jobs. We set $\delta_{L}=0.05$ and $\delta_{H}=0.04$ to capture this feature. These values correspond to an average job duration of $1 / 0.05=20$ and $1 / 0.04=25$ quarters for low and high productivity firms, respectively. The flow value of unemployment benefit $z$ is chosen to be equal to 0.6 , which is close to the average in the existing literature. The flow costs of opening a vacancy $c_{L}$ and $c_{H}$ are chosen to be equal to 0.1 and 0.33 , respectively, which are close by Shimer (2005) who assumes that the cost of a vacancy to be 0.213 . For a more detailed literature review see Stupnytska and Zaharieva (2017). We assume that firms pay an entry cost for per period of time, and it is equal to 0.6, which implies the discounted present value of the cost is $K=0.6 / 0.012=50$. Further, we set the elasticity of the matching function with respect to unemployment, $\alpha$, to vary between 0.4 and 0.6 , which is close to the values used by Petrongolo and Pissarides (2001). As for bargaining power, we assume that $\beta=\alpha=0.5$ so that Hosios condition holds. Petrongolo and Pissarides (2001) set $\beta$ to 0.5 and Shimer (2005) uses a larger value of 0.72 . The fraction of low-skilled workers $\mu$ is chosen to be equal to 0.6. Albrecht and Vroman (2002) use a value of 0.67 for this parameter. Brenzel et al (2014), focusing on the German labour market, show that the fraction of wage posting firms is two-thirds and the fraction of firms relying on Nash bargaining is one-third of total hirings. We set the fraction of low productivity firms to 0.6 and that of high productivity firms to 0.4 when the wage setting mechanism is exogenously given. Finally, we assume that the matching efficiency coefficient $m_{0}$ is equal to 0.56 . This parameter yields the equilibrium unemployment rates are $u_{L} / \mu=0.063$ and $u_{H} /(1-\mu)=0.10$ for low and high skilled workers, respectively. The values of baseline parameters are summarized in table 2 .

\subsection{Comparative statics}

We define as benchmark the case that in which the productivity levels are $y_{L}=1.25, y_{L H}=1.35$ and $y_{H}=1.45$. Our model shows that the total job surplus $S_{L}$ for low productivity firms can be an increasing or decreasing function in $\theta_{H}$. So that the relationship between the market tightnesses $\theta_{L}$ and $\theta_{H}$ implied by the job creation curve $\left(J C_{L}\right)$ can be a positive or negative. This effect of changes $\Delta y_{L}=[-0.05 . .1], \Delta y_{L H}=0$ and $\Delta y_{H}=0$ on benchmark case is illustrated in the left panel of figure 3. As we can see, the relationship between the market tightnesses is positive when the productivity level $y_{L}$ is below the productivity threshold $y_{L}^{*}$, while it is negative otherwise. Note that under our baseline parameter specification $y_{L}^{*}=1.289$. Moreover, the curve $\left(J C_{L}\right)$ implies a lower $\left(\underline{\theta_{L}}\right)$ and an upper bound $\left(\overline{\theta_{L}}\right)$ as described in Corollary 1. The right panel of figure 3 illustrates the job creation curve $\left(J C_{H}\right)$ for different level of $y_{H}$ and $\theta_{L}$. Similar, the curve $\left(J C_{H}\right)$ implies a lower $\left(\underline{\theta_{H}}\right)$ and an upper bound $\left(\theta_{H}\right)$ for $\theta_{H}$. Our choice of parameters implies that $\theta_{H}$ is increasing in $\theta_{L}$, asymptotically converging to its upper bound $\overline{\theta_{H}}$ as shown in Corollary 1.

The equilibrium market tightnesses $\theta_{L}$ and $\theta_{H}$ are determined by the intersection of two curves $\left(J C_{L}\right)$ and $\left(J C_{H}\right)$. We can observe in figure 4 that the decentralized equilibrium is unique in all our simulations. Moreover, the equilibrium values of $\theta_{L}$ and $\theta_{H}$ belong to the intervals $\left[\underline{\theta_{L}}, \overline{\theta_{L}}\right]$ and $\left[\underline{\theta_{H}}, \overline{\theta_{H}}\right]$, respectively. 

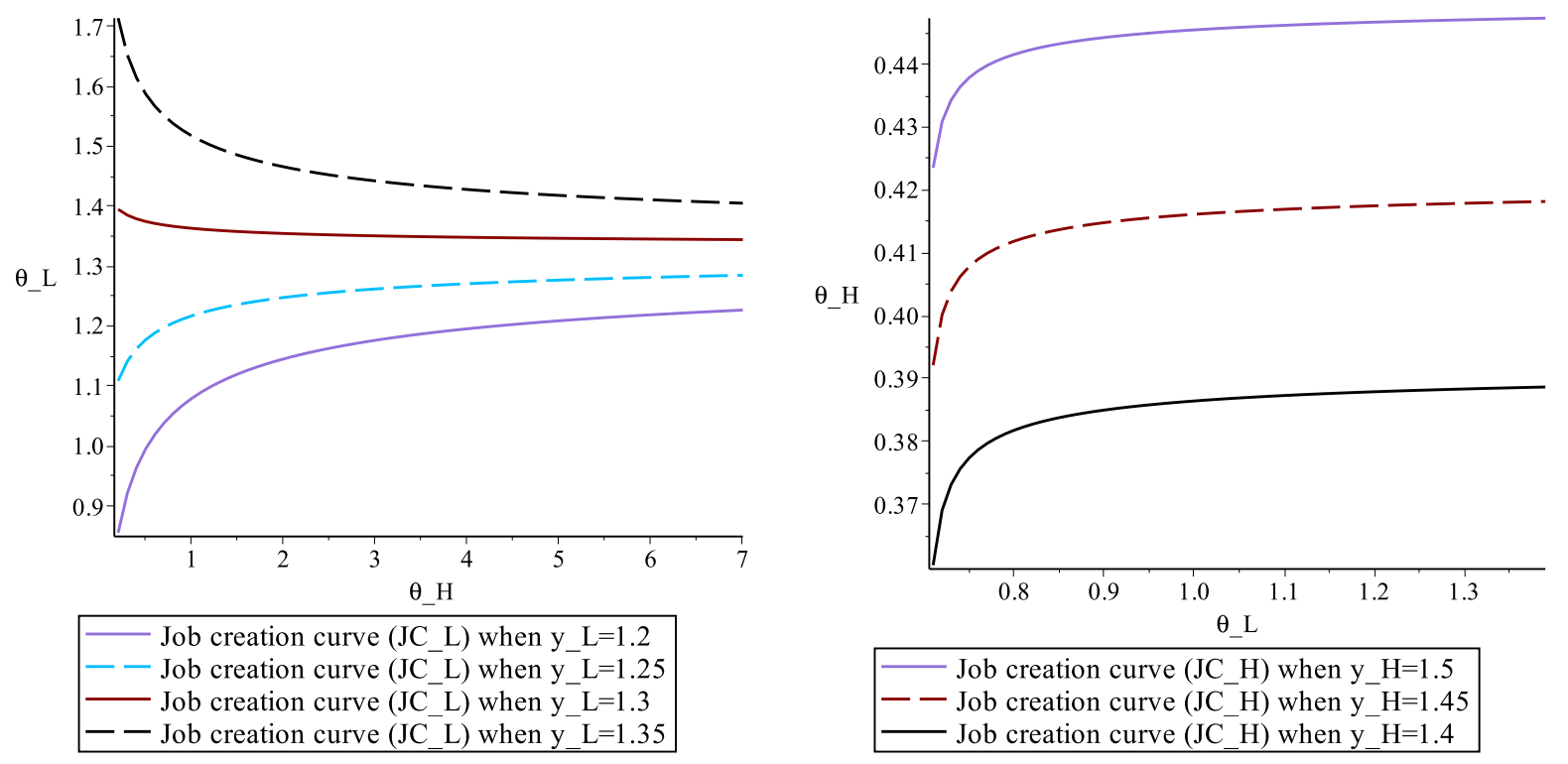

Figure 3: Left panel: $J C_{L}$ curve for different values of $y_{L}$ and $\theta_{H}$. Right panel: $J C_{H}$ curve for different values of $y_{H}$ and $\theta_{L}$.

Table 2: Baseline parameters

\begin{tabular}{lcl}
\hline Parameter & Value & Description \\
\hline$y_{L}$ & 1.25 & Productivity level of low productivity firms \\
$y_{L H}$ & 1.35 & Productivity level of low-skilled workers in high productivity firms \\
$y_{H}$ & 1.45 & Productivity level of high productivity firms \\
$r$ & 0.012 & Discount rate \\
$\delta_{L}$ & 0.05 & Job destruction rate for low productivity firms \\
$\delta_{H}$ & 0.04 & Job destruction rate for high productivity firms \\
$z$ & 0.6 & Unemployment benefit \\
$c_{L}$ & 0.1 & Flow cost of open vacancy for low productivity firms \\
$c_{H}$ & 0.33 & Flow cost of open vacancy for high productivity firms \\
$K$ & 50 & Entry cost \\
$\alpha$ & $0.4,0.6]$ & Matching elasticity \\
$m_{0}$ & 0.56 & Matching efficiency \\
$\beta$ & 0.5 & Bargaining power of workers \\
$\mu$ & 0.6 & Fraction of low-skilled workers \\
\hline
\end{tabular}

For the benchmark case, lower and upper bounds for $\theta_{L}$ are calculated as 0.416 and 1.331, respectively. In addition, $\theta_{L}$ asymptotically converges to 1.331 from below, as shown by the solid blue line in figure 4 . When the productivity level is changed to $y_{L}=1.3$ which is higher than the threshold $y_{L}^{*}$, the equilibrium market tightness $\theta_{L}$ is decreasing function in $\theta_{H}$ and asymptotically converges to 1.331 from above. Thus calculated upper and lower bounds for $\theta_{L}$ 
are become as 1.664 and 1.331, respectively. This effect is illustrated by the solid black line in figure 4 . We can see that $\theta_{L}$ is still increasing in $\theta_{H}$ and converges asymptotically to 1.331 from above when the productivity level $y_{L}$ is 1.35 as well. In this case, the curve $\left(J C_{L}\right)$ implies upper and lower bounds $\theta_{L}$ as 3.746 and 1.331. This is illustrated by the solid purple line.

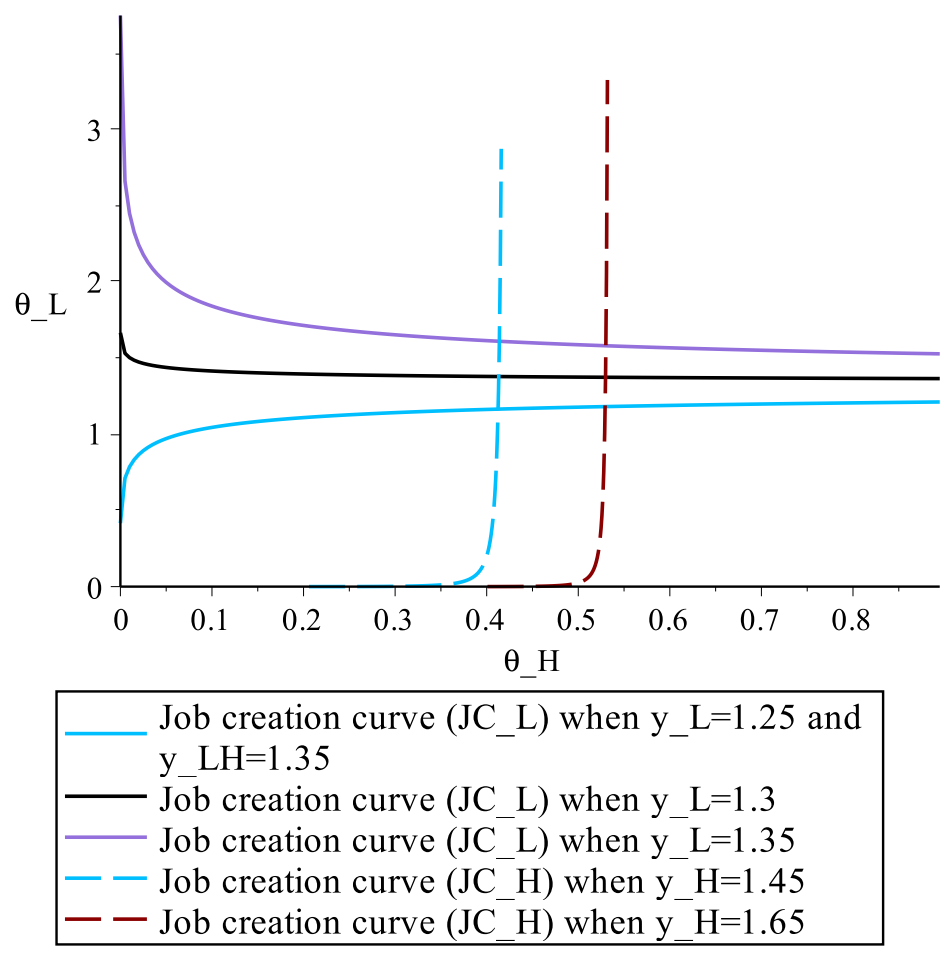

Figure 4: $J C_{L}$ and $J C_{H}$ curves for different values of $y_{L}$ and $y_{H}$

The curve $\left(J C_{H}\right)$ implies lower bound $\underline{\theta_{H}}$ and upper bound $\overline{\theta_{H}}$ as 0.188 and 0.422 , respectively, when the productivity level is given by $y_{H}=1.45$. When the productivity level $y_{H}$ increased to 1.65 , corresponding bounds become 0.370 and 0.535 , respectively. In figure 4 , these are illustrated by the dashed blue and red lines.

A question comes up naturally. What are the implications of higher productivities $y_{L}$ and $y_{H}$ for equilibrium market tightnesses? The model predicts that both market tightnesses increase in our baseline parameter settings. This result is intuitive, because firms expect higher profits and open more vacancies in both submarkets. Figure 4 also illustrates this effect of $\Delta y_{L}=[0 . .1]$, $\Delta y_{H}=0$ for the benchmark case and the effect of different scenario in which $\Delta y_{L}=0$ and $\Delta y_{H}=0.2$. When increasing $\Delta y_{L}$ and $\Delta y_{H}$, the $\left(J C_{L}\right)$ shifts upward, and $\left(J C_{H}\right)$ moves to the right. This finding is similar to that in Gautier (2002) and Stupnytska and Zaharieva (2017). Gautier (2002) finds that low-skill workers gain from the high productivity of high-skilled workers in simple jobs, while Stupnytska and Zaharieva (2017) emphasize that more vacancies are created in the regular and referral submarkets as high-ability workers search in both submarkets.

Figure 5 illustrates the effects of an increase in unemployment benefits for different values of productivity levels. As expected, the unemployment rates for both types of workers increase as the unemployment benefit $z$ increases.

The left panel of figure 6 illustrates the impact of unemployment benefits on the employment rate $e_{L H} / \mu$. The figure shows that the fraction of low-skilled workers employed by high 
productivity firms decreases as unemployment benefit increases. This is a consequence of a higher unemployment rate $u_{L} / \mu$. We can see that $e_{L H} / \mu$ shifts up as the productivity level $y_{L H}$ increases, as result of a lower unemployment rate for higher productivity level $y_{L H}$. Intuitively, when low-skilled workers become more productive high productivity firms expect higher profits, hence hiring more workers. The right panel of figure 6 focuses on the effect of increasing cost of opening a vacancy for high productivity firms $c_{H}$ on the employment rate $e_{L H} / \mu$ for different values of productivity level $y_{L H}=[1.3,1.35,1.4]$. The cost $c_{H}$ varies from 0.1 to 0.5 , and we can see again that the employment rate $e_{L H} / \mu$ decreases as of opening vacancy cost $c_{H}$ increases. The employment curve $e_{L H} / \mu$ shifts up when the productivity level $y_{L H}$ increases. These results are intuitive, because high productivity firms have an incentive to hire low-skilled employees, but it becomes more costly for them to do so as the cost of opening vacancy increases. As a result, fewer vacancies are created and less low-skilled workers are hired. However, when low-skilled employees become more productive, firms expect higher profits, which encourages them to hire more low-skilled workers, explaining the reason of the upward shift of $e_{L H} / \mu$ as the productivity level $y_{L H}$ increases.

Table 3 illustrates the changes in the fraction of two types of firms and in wage dispersion among workers, induced by an increase in the productivity level $y_{L}$. Note that it is more profitable for firms to open vacancies in the low productivity submarket than in the high productivity submarket for firms when $y_{L}$ increases. This follows from the fact that firms obtain the total job surplus because they use take-it-or-leave-it wage offers when they decide to open a vacancy in the low productivity submarket. At the same time, low-skilled workers have no incentives to change their jobs and to be employed at high productivity firms, since the difference between $y_{L}$ and $y_{L H}$ is diminished. Thus, low productivity firms can retain the current workers for a longer period of time. As a result, the fraction of low productivity firms increases from 0.523 to 0.556 when the productivity $y_{L}$ increases from 1.24 to 1.32 . Wage dispersion both within and across groups of workers $\left(\Delta w_{L}\right.$ and $\left.\Delta w_{H}\right)$ slightly increase. Overall, the impact of changes in $y_{L}$ on wage dispersion is negligible.

In contrast, the impact of changes in the productivity level $y_{L H}$ on wage dispersion is stronger. As low-skilled workers become more productive at high productivity firms, they open more vacancies and it becomes more attractive for low-skilled workers to change their jobs. Thus, unemployed low-skilled workers are willing to accept their initial jobs at low productivity firms, as a result, and their reservation wages decrease significantly in the equilibrium. This effect is illustrated in table 4. This results in higher wage dispersion among workers, in particular within group. We can observe that profits of two types of firms increase as well. On the one hand, it is profitable for firms to open vacancies in the low productivity submarket, as the reservation wages of low-skilled workers decrease. On the other hand, it is also profitable for firms to open vacancies in the high productivity submarket, because they can hire more experienced low-skilled workers.

Further, table 5 presents the effect of changes in the productivity level $y_{H}$. In our setup, we find that opening more vacancies by high productivity firms has a positive effect on low productivity firms, since it entails that the equilibrium reservation wages of low-skilled workers diminish. This finding is similar to Albrecht and Vroman (2002), although they find skill-biased technological change has a negative effect on low-skilled workers, we find a positive effect instead. 


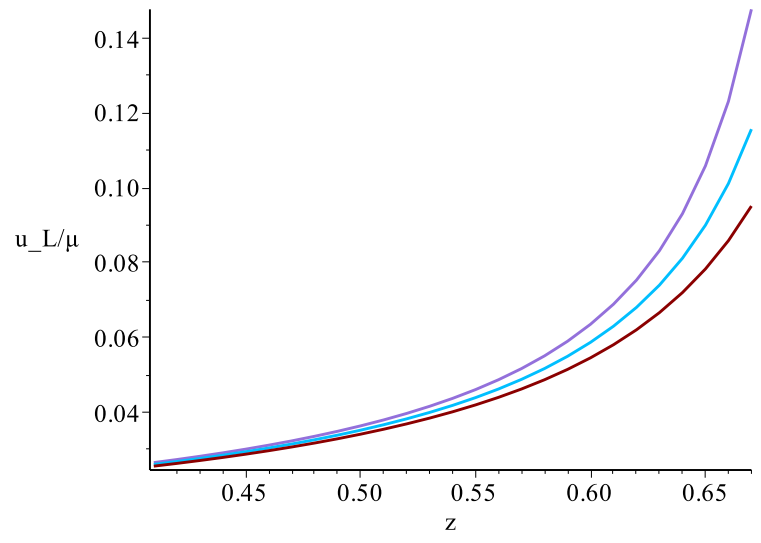

Unemployment $\left(u_{-} L / \mu\right)$ when y_L $=1.25$, y_LH=1.35 and $\mathrm{y}_{-} \mathrm{H}=1.45$

Unemployment $\left(\mathrm{u} \_\mathrm{L} / \mu\right)$ when y_L $=1.3$, y_LH $=1.35$ and $\mathrm{y}_{-} \mathrm{H}=1.45$

Unemployment $\left(\mathrm{u} \_\mathrm{L} / \mu\right)$ when $\mathrm{y}_{-} \mathrm{L}=1.35, \mathrm{y} \_\mathrm{LH}=1.35$ and $\mathrm{y}_{2} \mathrm{H}=1.45$

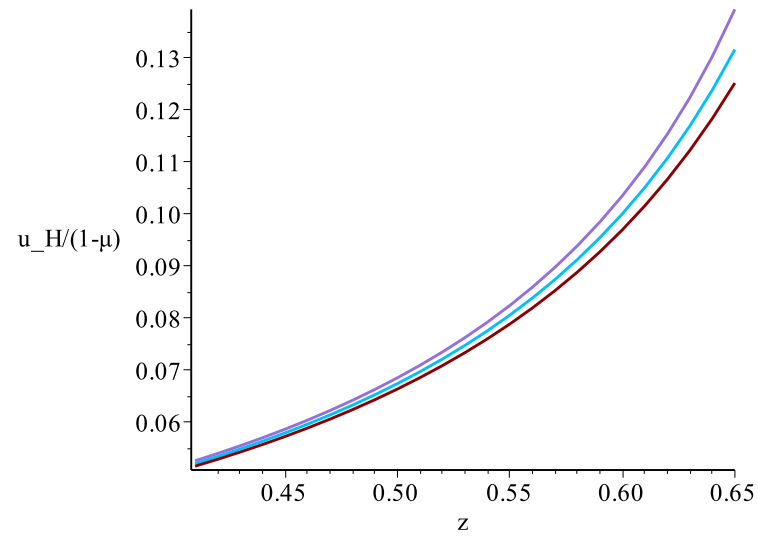

Unemployment $\left(\mathrm{u}_{-} \mathrm{H} /(1-\mu)\right)$ when y_L $=1.25$, y_LH= 1.35 and $\mathrm{y} \mathrm{H}=1.4$

Unemployment $\left(\mathrm{u}_{-} \mathrm{H} /(1-\mu)\right)$ when y_L $=1.25$, y_LH=

1.35 and $\mathrm{y}_{-} \mathrm{H}=1.4 \overline{5}$

Unemployment $\left(\mathrm{u} \_\mathrm{H} /(1-\mu)\right)$ when y_L $=1.25$, y_LH=

1.35 and $\mathrm{y}_{2} \mathrm{H}=1.5$

Figure 5: Changes in unemployment rates $u_{L} / \mu$ and $u_{H} /(1-\mu)$ with increase in unemployment benefit $z$ for different productivity levels $y_{L}$ and $y_{H}$

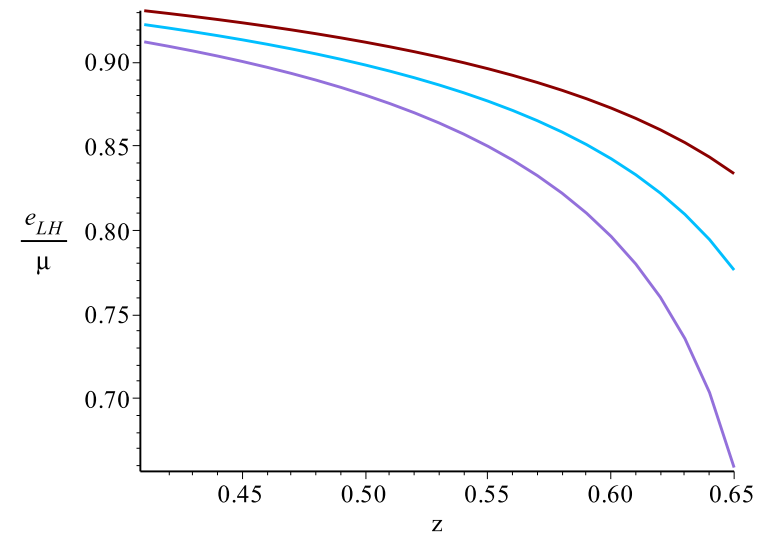

Employment $(\mathrm{e} \mathrm{LH} / \mu)$ when y $\mathrm{L}=1.25$, y $\mathrm{LH}=1.3$ and $\mathrm{y}_{-} \mathrm{H}=1.45$

Employment (e $\mathrm{LH} / \mu$ ) when y $\mathrm{L}=1.25$, y $\mathrm{LH}=1.35$ and $\mathrm{y}_{-} \mathrm{H}=1.45$

Employment (e_LH/ $\mu$ ) when y_L=1.25, y_LH=1.4 and $\mathrm{y}_{2} \mathrm{H}=1.45$

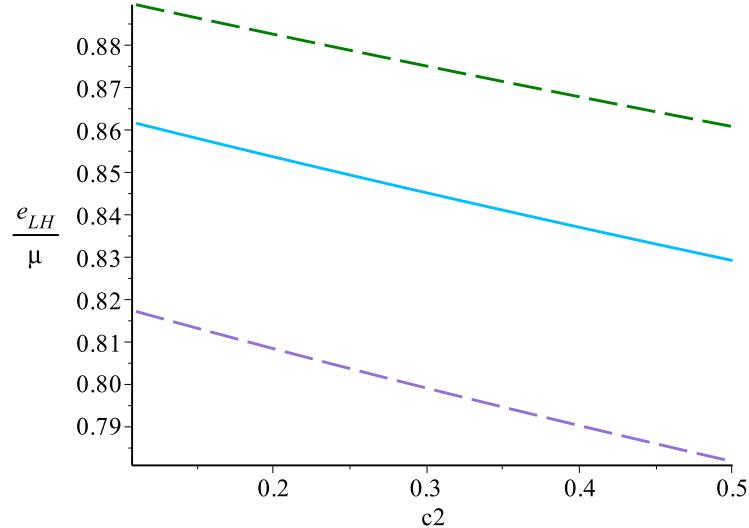

_ Employment $\left(\mathrm{e} \_\mathrm{LH} / \mu\right)$ when y L $=1.25$, y $\mathrm{LH}=1.3$ and $\mathrm{y}_{-} \mathrm{H}=1.45$

Employment $(\mathrm{e}-\mathrm{LH} / \mu)$ when y $\mathrm{L}=1.25$, y $\mathrm{LH}=1.35$ and $\mathrm{y}_{-} \mathrm{H}=1.45$

_ _ Employment $\left(\mathrm{e} \_\mathrm{LH} / \mu\right)$ when y_L $=1.25$, y_LH=1.4 and $\mathrm{y}_{-} \mathrm{H}=1.45$

Figure 6: Changes in employment rates $e_{L H} / \mu$ when unemployment benefit $z$ and cost of opening a vacancy $\operatorname{cost} c_{H}$ increase.

Table 3: Comparative statics: $y_{L H}=1.35, y_{H}=1.45, \beta=0.5, \alpha=0.5$

\begin{tabular}{cccccccc}
\hline & $\eta$ & $\theta_{L}$ & $\theta_{H}$ & $S_{L}$ & $(1-\beta)\left[(1-\gamma) S_{L H}+\gamma S_{H}\right]$ & $\Delta w_{L}$ & $\Delta w_{H}$ \\
$y_{L}=1.24$ & 0.523 & 1.123 & 0.412 & 1.325 & 1.066 & 0.5936 & 0.14696 \\
$y_{L}=1.28$ & 0.540 & 1.290 & 0.4130 & 1.419 & 1.067 & 0.5940 & 0.14697 \\
$y_{L}=1.32$ & 0.556 & 1.468 & 0.4136 & 1.514 & 1.068 & 0.5944 & 0.14699 \\
\hline
\end{tabular}


We can see that the difference in the expected profits by opening vacancies in two submarkets diminishes as the productivity level $y_{H}$ increases. For example, for $y_{H}=1.4$ the profit difference is $S_{L}-(1-\beta)\left[(1-\gamma) S_{L H}+\gamma S_{H}\right]=0.318$ and it decreases to 0.247 for $y_{H}=1.5$. It implies that the increase in the expected profit of high productivity firms is higher than the of low productivity firms. Thus, more firms open vacancies in the high productivity submarket and the fraction of high productivity firms $(1-\eta)$ increases from 0.463 to 0.482 when $y_{H}$ increases from 1.4 to 1.5. It entails a higher wage dispersion both within and across groups of workers which equal to 0.612 and 0.192 , respectively.

Table 4: Comparative statics: $y_{L}=1.25, y_{H}=1.45, \beta=0.5, \alpha=0.5$

\begin{tabular}{lccccccc}
\hline & $\eta$ & $\theta_{L}$ & $\theta_{H}$ & $S_{L}$ & $(1-\beta)\left[(1-\gamma) S_{L H}+\gamma S_{H}\right]$ & $\Delta w_{L}$ & $\Delta w_{H}$ \\
$y_{L H}=1.35$ & 0.527 & 1.164 & 0.412 & 1.348 & 1.066 & 0.593 & 0.146 \\
$y_{L H}=1.4$ & 0.540 & 2.042 & 0.630 & 1.786 & 1.318 & 0.955 & 0.126 \\
$y_{L H}=1.45$ & 0.548 & 3.203 & 0.905 & 2.237 & 1.580 & 1.405 & 0.104 \\
\hline
\end{tabular}

Table 5: Comparative statics: $y_{L}=1.25, y_{L H}=1.35, \beta=0.5, \alpha=0.5$

\begin{tabular}{cccccccc}
\hline & $\eta$ & $\theta_{L}$ & $\theta_{H}$ & $S_{L}$ & $(1-\beta)\left[(1-\gamma) S_{L H}+\gamma S_{H}\right]$ & $\Delta w_{L}$ & $\Delta w_{H}$ \\
$y_{H}=1.4$ & 0.537 & 1.159 & 0.382 & 1.345 & 1.027 & 0.574 & 0.101 \\
$y_{H}=1.5$ & 0.518 & 1.169 & 0.442 & 1.351 & 1.104 & 0.612 & 0.192 \\
$y_{H}=1.6$ & 0.502 & 1.177 & 0.500 & 1.356 & 1.175 & 0.646 & 0.283 \\
\hline
\end{tabular}

These results are inline with empirical evidences. For example, Dustmann and Meghir (2005) show that unskilled workers gain more by changing their jobs and job mobility is an important source of wage growth for workers in Germany. Another recent study by Del Bono and Vuri (2011) finds that job mobility explains close to $30 \%$ of total log wage growth for men and $8.3 \%$ for women in Italy. They emphasize that this difference is mainly due to the gender differences in returns to mobility and values of jobs.

Table 6: Comparative statics: $y_{L}=1.25, y_{L H}=1.35, y_{H}=1.45, \beta=0.5, \alpha=0.5$

\begin{tabular}{cccccccc}
\hline & $\eta$ & $\theta_{L}$ & $\theta_{H}$ & $S_{L}$ & $(1-\beta)\left[(1-\gamma) S_{L H}+\gamma S_{H}\right]$ & $\Delta w_{L}$ & $\Delta w_{H}$ \\
$\mu=0.4$ & 0.461 & 1.143 & 0.309 & 1.336 & 0.924 & 0.524 & 0.143 \\
$\mu=0.5$ & 0.499 & 1.154 & 0.356 & 1.342 & 0.991 & 0.557 & 0.145 \\
$\mu=0.6$ & 0.527 & 1.164 & 0.412 & 1.348 & 1.066 & 0.593 & 0.146 \\
$\mu=0.7$ & 0.548 & 1.174 & 0.478 & 1.354 & 1.149 & 0.633 & 0.148 \\
\hline
\end{tabular}



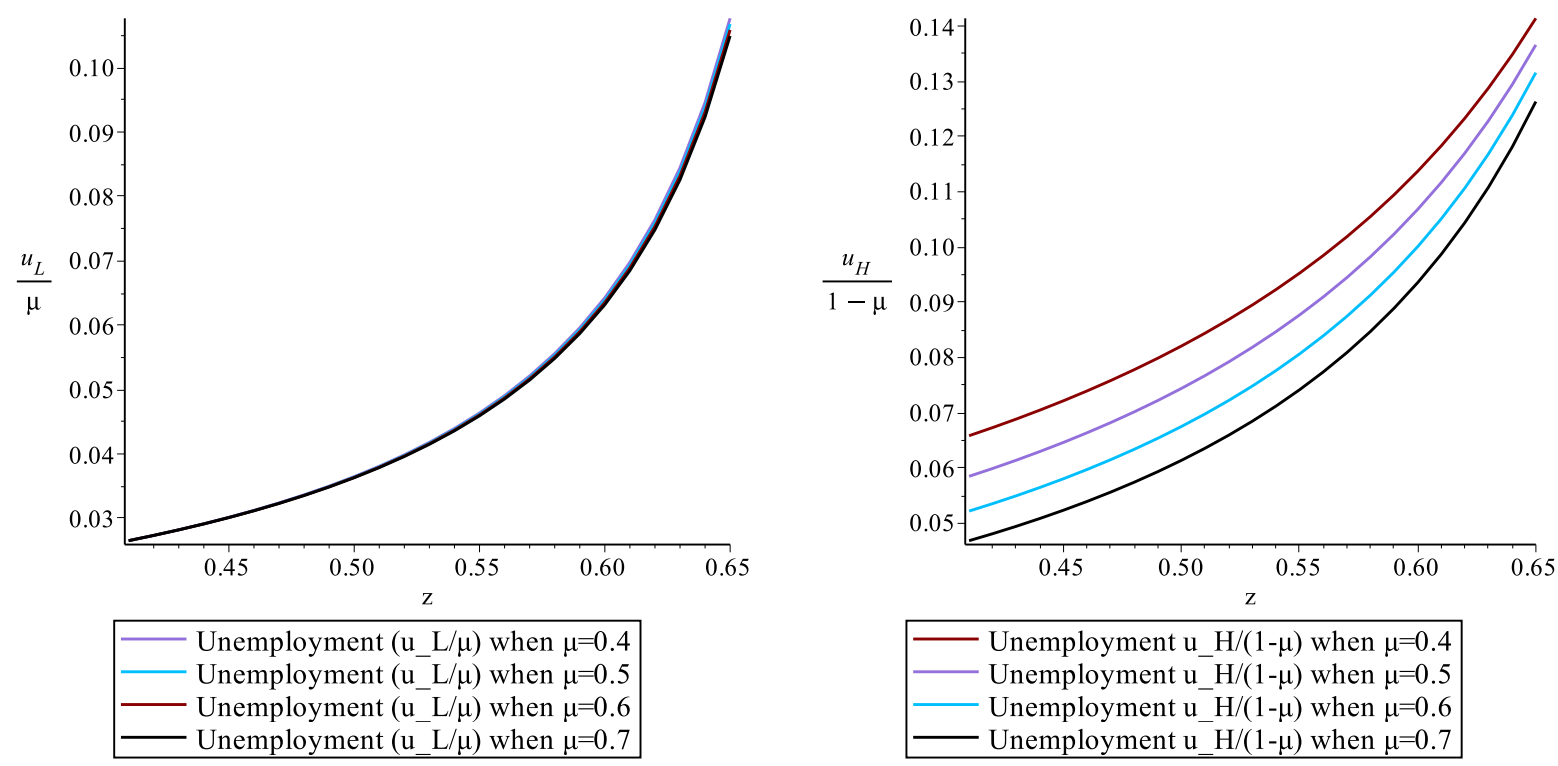

Figure 7: Changes in unemployments $u_{L} / \mu$ and $u_{H} /(1-\mu)$ with increase in unemployment benefit $z$ for different level of $\mu$

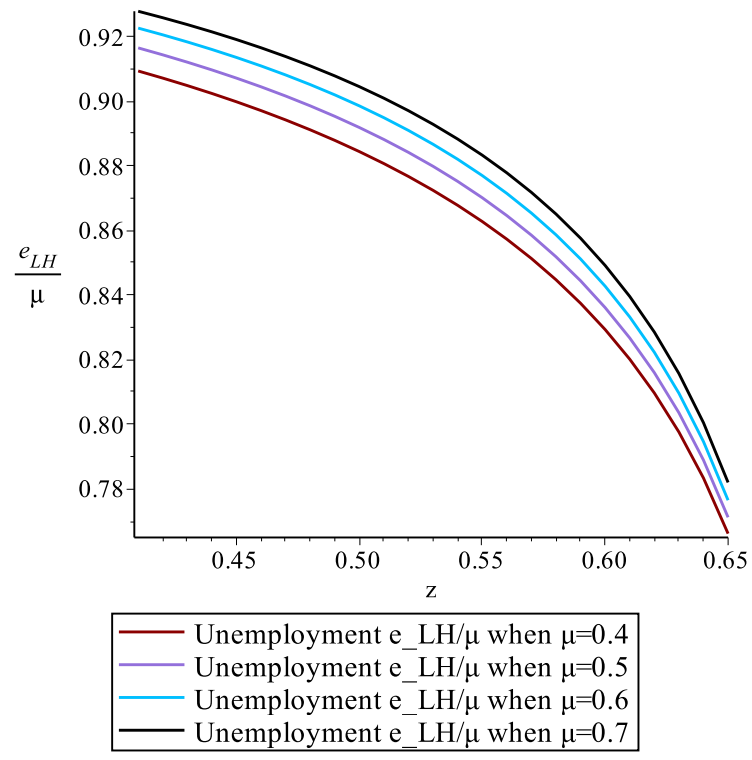

Figure 8: Changes in employment $e_{L H} / \mu$ with increase in unemployment benefit $z$ for different level of $\mu$

Finally, let us consider the effect of workers' skill composition. As mentioned before, in our benchmark economy the job creation curve $\left(J C_{H}\right)$ implies a positive relationship between two market tightnesses $\theta_{L}$ and $\theta_{H}$. When the fraction of low-skilled workers increases, profits of both types of firms increase. On the one hand, low productivity firms gain higher profits by paying lower wages to low-skilled workers, as supply of low-skilled workers increase. On the other hand, more low-skilled workers get experienced and they start looking for better paid jobs at high productivity firms. The high productivity firms open more vacancies, since it is also profitable for them to hire more experienced low-skilled workers. These relationships are illustrated in table 6. The expected profit of low productivity firms $S_{L}$ increases from 1.336 to 1.354 as the 
fraction of low-skilled workers $\mu$ increases from 0.4 to 0.7 . Similar, the expected profit of high productivity firms $(1-\beta)\left[(1-\gamma) S_{L H}+\gamma S_{H}\right]$ increases from 0.924 to 1.149 .

This mechanism reduces the reservation wages of low-skilled workers even more, as they expect to find a better job in the future. On the other hand, it is easy to find jobs for high-skilled workers, as the supply of high productivity vacancies increases. As a result, the bargained wages increase for high-skilled workers as well. Therefore, when the fraction of low-skilled workers $\mu$ increases to 0.7 the wage dispersion within $\left(\Delta w_{L}\right)$ and across $\left(\Delta w_{H}\right)$ group of workers increase to 0.633 and 0.148, respectively. Similar results are obtained by Machin and Manning (1997), Acemoglu (1999) and Albrecht and Vroman (2002) in the sense that the increase in supply of experienced low-skilled workers encourages firms to create more high productivity jobs, and leads to greater wage dispersion. Further, figure 7 shows that the unemployment curves of low and high skilled workers shift down as $\mu$ increases, while both unemployment rates increase as unemployment benefit $z$ increases. For example, when $z$ is fixed to 0.4 , for $\mu=0.4$ the equilibrium unemployment rates $u_{L} / \mu$ and $u_{H} /(1-\mu)$ are 0.025 and 0.064 , respectively. These numbers are changed to 0.025 and 0.050 , respectively, when $\mu$ increases to 0.6 . Figure 8 reveals that a large number of experienced low-skilled workers change their jobs for higher values of $\mu$. The employment rate $e_{L H} / \mu=0.911$ for $\mu=0.4$ and this number increases to 0.929 for $\mu=0.7$ when $z=0.4$. This indicates that low-skilled workers are willing to use their employment opportunities at high productivity firms.

\subsection{Exogenous participation}

In this section, we analyze the decentralized and centralized equilibrium outcomes under the assumption that the fraction of two types of firms is exogenously given. Following Brenzel et al (2014), we set the fraction of low productivity firms $\eta$ to 0.6. The rest of parameters are set the same as benchmark case. Table 7 presents the numerical results for different values of the matching elasticity $\alpha=[0.4,0.5,0.6]$. We can see that the decentralized equilibrium is not constraint efficient in all three cases. The equilibrium reservation wages are inefficiently low for low-skilled workers, while the bargained wages are inefficiently high for high-skilled workers. The equilibrium unemployment rates are also inefficiently low for both submarkets. For example, the unemployment rate for low-skilled workers $u_{L} / \mu$ is 0.055 in the decentralized equilibrium while it is 0.133 in the centralized equilibrium when we fix $\alpha=0.5$.

In the standard case, one could expect that a higher market tightness improves the outside options of unemployed workers and increase their reservation wages. However, in our model, this mechanism works differently for unemployed low-skilled workers due to their on-the-job search activity. Lower wages are acceptable for the low-skilled workers as they expect to find better paid jobs at high productivity firms in the future. Thus, low productivity firms expect high profit by paying low wages to these workers and they create more vacancies. As a result, the equilibrium reservation wage and unemployment rate for low-skilled workers are inefficiently low. When more low-skilled workers get experienced, the probability of jobs being filled with low-skilled workers for high productivity increases significantly. Hence high productivity firms also gain greater profit by creating more vacancies. Therefore, the equilibrium bargained wages and unemployment rate for high-skilled workers are inefficiently high and low, respectively. 


\subsection{Endogenous participation}

In this section, we provide similar analysis to the previous section when the endogenous choice of the wage setting mechanism is considered. Firms are allowed to open vacancies either for the low and for the high productivity submarket. Table 8 presents that the decentralized equilibrium is not constraint efficient again even if the Hosios condition is met $(\beta=\alpha=0.5)$. Further, we can observe the co-existence of both wage setting mechanisms in our numerical results. Meaning that the both types of firms emerge in the equilibrium when firms are allowed to open vacancies in both submarkets. This contradicts the results of Ellingsen and Rosen (2003) who find that firms choose open vacancies only in the high productivity submarket and adopt Nash bargaining wage determination in the equilibrium.

In our framework the main mechanism, which differs is the on-the-job search activity by lowskilled workers, affects the equilibrium wages of workers. As explained in the previous section, it is still attractive for firms to open vacancies in the low productivity submarket as they expect high profits by paying significantly low wages to low-skilled workers. As a result, the equilibrium employment rates and the reservation wages for low-skilled workers are inefficiently high and low, respectively. For example, for $\alpha=0.5$, in the decentralized equilibrium employment rate $\left(1-u_{L} / \mu\right)$ and reservation wage $w_{L}^{*}$ are 0.937 and 0.081 , respectively. The corresponding numbers become 0.803 and 0.319 , respectively, in the centralized equilibrium. It is also attractive for firms to open vacancies in high productivity submarket as they expect high profit by filling their jobs with experienced low-skilled workers more easily. Therefore, both types of wage setting mechanism coexist in the equilibrium. In table 8 we can see that the decentralized equilibrium shares of low productivity firms $\eta$ is 0.527 and it is higher than the socially efficient level (0.374) when $\alpha=0.5$.

Overall, under both exogenous and endogenous wage setting the traditional Hosios condition can not fully internalize all externalities, and the optimal redistribution policy is needed in order to restore socially efficient outcomes. The next subsection provides numerical results for the optimal policy instruments.

\subsection{The optimal policy}

This subsection analyzes the effect of the policy $\left\{\tau_{L}, \tau_{H}, T\right\}$ on labour market outcomes. We focus solely on the case of endogenous choice of the wage setting mechanism. As mentioned in section $3, \tau_{L}$ and $\tau_{H}$ are the flow values of transfers that unemployed low and high skilled workers receive from the public budget, respectively, and $T$ is the flow value of transfer that all workers contribute to the budget. We propose a simple policy which is intended to close the wedge between centralized and decentralized outcomes.

As noticed in section 5.3, the aim of this policy is to improve and worsen outside opportunities for low and high skilled workers, respectively. Given our parameterization of the model, the values of policy instruments are given by $\tau_{L}=0.083, \tau_{H}=0.107, T=0.016$. We compare two cases, namely, without policy and with policy including transfers $\tau_{L}, \tau_{H}$ and $T$ for workers. 
Table 7: Comparison between decentralized and centralized outcomes: $\alpha=[0.4,0.5,0.6]$ and $\beta=0.5$

\begin{tabular}{lcccccc}
\hline \multirow{2}{*}{ Variables } & \multicolumn{2}{c}{$(\beta>\alpha)$} & \multicolumn{2}{c}{$(\beta=\alpha)$} & \multicolumn{2}{c}{$(\beta<\alpha)$} \\
& Decentralized & Centralized & Decentralized & Centralized & Decentralized & Centralized \\
\hline$u_{L} / \mu$ & 0.050 & 0.125 & 0.055 & 0.133 & 0.059 & 0.133 \\
$u_{H} /(1-\mu)$ & 0.137 & 0.254 & 0.112 & 0.222 & 0.095 & 0.191 \\
$e_{L L} / \mu$ & 0.130 & 0.222 & 0.105 & 0.192 & 0.090 & 0.165 \\
$e_{L H} / \mu$ & 0.818 & 0.652 & 0.838 & 0.673 & 0.850 & 0.700 \\
$v_{L}$ & 0.052 & 0.026 & 0.052 & 0.019 & 0.051 & 0.013 \\
$v_{H}$ & 0.034 & 0.017 & 0.034 & 0.012 & 0.034 & 0.008 \\
$w_{L}^{*}$ & 0.239 & 0.430 & 0.143 & 0.398 & 0.055 & 0.356 \\
$w_{L H}$ & 0.675 & 0.675 & 0.675 & 0.675 & 0.675 & 0.675 \\
$w_{H}$ & 0.813 & 0.791 & 0.819 & 0.796 & 0.822 & 0.802 \\
$w_{H}^{*}$ & 0.776 & 0.732 & 0.788 & 0.743 & 0.795 & 0.754 \\
\hline
\end{tabular}

Table 8: Comparison between decentralized and centralized outcomes: $\alpha=[0.4,0.5,0.6]$ and $\beta=0.5$

\begin{tabular}{lcccccc}
\hline Variables & \multicolumn{2}{c}{$(\beta>\alpha)$} & \multicolumn{2}{c}{$(\beta=\alpha)$} & \multicolumn{2}{c}{$(\beta<\alpha)$} \\
& Decentralized & Centralized & Decentralized & Centralized & Decentralized & Centralized \\
\hline$\eta$ & 0.523 & 0.361 & 0.527 & 0.374 & 0.531 & 0.385 \\
$u_{L} / \mu$ & 0.062 & 0.222 & 0.063 & 0.197 & 0.064 & 0.173 \\
$u_{H} /(1-\mu)$ & 0.117 & 0.172 & 0.100 & 0.170 & 0.088 & 0.159 \\
$e_{L L} / \mu$ & 0.109 & 0.134 & 0.093 & 0.136 & 0.082 & 0.132 \\
$e_{L H} / \mu$ & 0.827 & 0.642 & 0.842 & 0.665 & 0.852 & 0.694 \\
$v_{L}$ & 0.044 & 0.014 & 0.044 & 0.010 & 0.044 & 0.007 \\
$v_{H}$ & 0.040 & 0.025 & 0.039 & 0.018 & 0.039 & 0.012 \\
$w_{L}^{*}$ & 0.165 & 0.324 & 0.081 & 0.319 & 0.007 & 0.296 \\
$w_{L H}$ & 0.675 & 0.675 & 0.675 & 0.675 & 0.675 & 0.675 \\
$w_{H}$ & 0.817 & 0.805 & 0.821 & 0.806 & 0.824 & 0.808 \\
$w_{H}^{*}$ & 0.785 & 0.761 & 0.793 & 0.762 & 0.799 & 0.767 \\
\hline
\end{tabular}

In order to understand the effects of this policy, we introduce two new welfare variables $\Omega_{L}$ and $\Omega_{H}$ for low and high-skilled workers, respectively, i.e., 


$$
\begin{array}{r}
\Omega_{L}=u_{L}\left(z+\tau_{L}-T\right)+\left(\mu-u_{L}-e_{L H}\right)\left(y_{L}-r K-T\right)+e_{L H}\left(y_{L H}-r K-T\right)- \\
-\theta_{L} u_{L}\left(c_{L}+r K\right)-\theta_{H}\left(\mu-u_{L}-e_{L H}\right)\left(c_{H}+r K\right), \\
\Omega_{H}=u_{H}\left(z+\tau_{H}-T\right)+\left(1-\mu-u_{H}\right)\left(y_{H}-r K-T\right)-\theta_{H} u_{H}\left(c_{H}+r K\right) .
\end{array}
$$

In the expression for $\Omega_{L}$ the first term is the inflow income of unemployed low-skilled workers, the second and third terms are the flow output of employed low-skilled workers in the low and high productivity firms, respectively, and the last two terms are the cost of job creation for both submarkets. Similar, in the expression for $\Omega_{H}$, the first term is the inflow income of unemployed high-skilled workers, the second term is the flow output of employed high-skilled workers, and the third term is the cost of job creation in the high productivity submarket. Note that transfers are purely redistributive, i.e., $u_{L} \tau_{L}+u_{H} \tau_{H}=T$.

Let us analyze the effect of this policy. Table 9 shows that transfers $\left\{\tau_{L}, \tau_{H}, T\right\}$ increase the equilibrium unemployment rate of low-skilled workers $u_{L} / \mu$ and raise their reservation wages $w_{L}^{*}$. The unemployment rate of high-skilled workers $u_{H} /(1-\mu)$ is also increased, while their bargained wages $w_{H}$ are slightly decreased due to worsened bargaining positions. This result is driven by reduction of market tightnesses in both submarkets, which entail a higher competition among workers. This policy mitigates the positive effect of high productivity firms on low productivity firms. Namely, since fewer number of vacancies $v_{H}$ are created for high productivity firms, it is not attractive to accept significantly lower reservation wages for low-skilled workers and get an opportunity to change their jobs to high productivity firms in the future. Thus, compared to case without policy, it is less profitable for low productivity firms to create vacancies, so they respond to this situation by creating fewer number of vacancies $v_{L}$.

Further, table 10 presents that the wage dispersion within and across groups of workers $\Delta w_{L}$ and $\Delta w_{H}$ decrease due to higher reservation wage for low-skilled workers and lower bargained wage for high-skilled workers. The expected profits for both types of firms, $S_{L}$ and $(1-\beta)[(1-$ $\left.\gamma) S_{L H}+\gamma S_{H}\right]$, diminish when the policy is implemented. In particular, subsidizing workers reduces the profits of low productivity firms $S_{L}$ from 1.348 to 0.378 , reflecting the increase in reservation wages for low-skilled workers.

Table 9: Optimal policy $\tau_{L}=0.083, \tau_{H}=0.107, T=0.016$ in a labour market with $y_{L}=1.25$, $y_{L H}=1.35$ and $y_{H}=1.45$

\begin{tabular}{lcccccccccc}
\hline \hline Optimal policy & $\theta_{L}$ & $\theta_{H}$ & $u_{L} / \mu$ & $u_{H} /(1-\mu)$ & $e_{L H} / \mu$ & $w_{L}^{*}$ & $w_{H}^{*}$ & $w_{H}$ & $v_{L}$ & $v_{H}$ \\
\hline Without policy & 1.164 & 0.412 & 0.063 & 0.100 & 0.842 & 0.081 & 0.793 & 0.821 & 0.044 & 0.039 \\
With policy & & & & & & & & & & \\
$\left\{\tau_{L}, \tau_{H}, T\right\}$ & 0.091 & 0.120 & 0.197 & 0.170 & 0.665 & 0.552 & 0.800 & 0.825 & 0.010 & 0.018 \\
\hline
\end{tabular}


Table 10: Optimal policy $\tau_{L}=0.083, \tau_{H}=0.107, T=0.016$ in a labour market with $y_{L}=1.25$, $y_{L H}=1.35$ and $y_{H}=1.45$

\begin{tabular}{lcccccccc}
\hline \hline Optimal policy & $\Delta w_{L}$ & $\Delta w_{H}$ & $S_{L}$ & $(1-\beta)\left[(1-\gamma) S_{L H}+\gamma S_{H}\right]$ & $\gamma$ & $\Omega_{L}$ & $\Omega_{H}$ & $\eta$ \\
Without policy & 0.593 & 0.146 & 1.348 & 1.066 & 0.415 & 0.386 & 0.314 & 0.527 \\
& & & & & & & & \\
With policy & & & & & & & & \\
$\left\{\tau_{L}, \tau_{H}, T\right\}$ & 0.162 & 0.109 & 0.378 & 0.576 & 0.453 & 0.406 & 0.315 & 0.374 \\
\hline
\end{tabular}

As for the expected profit $(1-\beta)\left[(1-\gamma) S_{L H}+\gamma S_{H}\right]$ for high productivity firms, there two counteracting effects of $\theta_{H}$ and $\gamma$. On the one hand, a lower equilibrium market tightness $\theta_{H}$ increases the job surplus $S_{H}$ and increases the probability of meeting a high-skilled worker $\gamma$, so it results in a positive effect on expected profits. On the other hand, lower probability of meeting a low-skilled worker $(1-\gamma)$ entails a greater reduction in the job surplus term $(1-\gamma) S_{L H}$, thus having a negative effect on expected profits. Depending on which effect dominates, the equilibrium expected profits may increase or decrease. In our numerical example, negative effect dominates, so that expected profits for high productivity firms decrease when the policy is implemented.

Moreover, the equilibrium ratio between the two types of firms $\eta /(1-\eta)$ is determined by the ratio between two market tightnesses and the job seekers ratio in two submarkets: $\theta_{L} / \theta_{H}$ and $u_{L} /\left(u_{H}+e_{L L}\right)$. Correlations of these two ratios with the ratio of two types of firms have different signs: the former one is positively while the latter one is negatively related to the ratio of two types of firms $\eta /(1-\eta)$. In general, the equilibrium fraction of $\eta$ can increase or decrease depending on which of the two effects dominates. Note that the market tightnesses ratio is 2.822 and the job seekers ratio equals to 0.396 in the absence of policy, while the first ratio decreases to 0.760 and the second increases to 0.787 when the policy is implemented. Nonetheless, the negative effect dominates, so that the equilibrium ratio between two types of firms $\eta /(1-\eta)$ is decreased. The equilibrium value of $\eta$ is 0.374 when the policy is implemented, and is 0.527 in the absence of the policy. Intuitively, this policy implies that opening a vacancy in the low productivity submarket yields a lower profit than opening in the high productivity submarket. Indeed, $S_{L}$ is 0.378 while $(1-\beta)\left[(1-\gamma) S_{L H}+\gamma S_{H}\right]$ is equal to 0.576 . Thus, the equilibrium fraction of low productivity firms $\eta$ is decreased when the policy is implemented.

Overall, our numerical results reveal that the proposed policy implies a welfare gain for both types of workers $\Omega_{L}$ and $\Omega_{H}$. We find that $\Omega_{L}$ is 0.3860 for low-skilled workers without policy and is 0.4066 with the policy when the Hosios condition holds $(\beta=\alpha=0.5)$. Similar, $\Omega_{H}$ is 0.3146 for high-skilled workers without policy and is 0.3158 with the policy. The total net gain from the policy is approximately $3.02 \%$. In addition, the equilibrium wage dispersion is reduced and this policy enables to restore the socially efficient outcomes.

It is worth asking how the optimal policy changes if the Hosios condition is not met, i.e., $\beta \neq \alpha$. In this case, both firms and workers are affected by search externalities. Therefore, the optimal transfers to unemployed workers should be modified to account for these externalities.

When $\beta<\alpha$, firms generate greater search externalities for each other due to low job filling rates $q\left(\theta_{L}\right)$ and $q\left(\theta_{H}\right)$ in the corresponding submarkets. Meaning that it becomes harder to fill 
open vacancies and every additional vacancy in the submarket negatively affects vacancies in the same submarket. The equilibrium wage is lower than socially optimal level for low-skilled workers while it is inefficiently higher for high-skilled workers although too many vacancies are created in both submarkets. Therefore, the transfers $\left\{\tau_{L}, \tau_{H}, T\right\}$ should be modified to increase the reservation wage for low-skilled workers and to weaken bargaining positions of high-skilled workers, thus achieving lower expected profits for both types of firms. As a result, both types of workers will receive positive value of transfers $\tau_{L}$ and $\tau_{H}$. Intuitively, lower profits make vacancies less attractive to the new entrants which mitigates the negative externality.

When $\beta>\alpha$, workers generate greater search externalities for each other due to low job finding rates $\lambda\left(\theta_{L}\right)$ and $\lambda\left(\theta_{H}\right)$ in the corresponding submarkets. In this case, it is hard to find jobs and every additional searching worker negatively affects other job seekers. The equilibrium wage is still inefficiently low for low-skilled workers and inefficiently high for high-skilled workers. Therefore, the transfers $\left\{\tau_{L}, \tau_{H}, T\right\}$ should be modified to achieve higher expected worker rents for low-skilled workers and lower expected worker rents for high-skilled workers. Thus, lowskilled workers will receive an unambiguously positive transfer $\tau_{L}$, and high-skilled workers will be more likely to receive a negative transfer $\tau_{H}$. Intuitively, a lower expected gain from the job makes searching workers less sensitive to the number of job seekers, which mitigates the negative externality.

Table 11 presents the changes of social welfare variables for different values of bargaining power $\beta$ and together with corresponding the list of optimal policy instruments. Note that the welfare variables $\Omega_{L}, \Omega_{H}$ and $\Omega_{L}+\Omega_{H}$ have unique maximal values for $\beta \in[0,1]$. To understand the effect of changes in bargaining power, we consider deviations of $\beta$ around the Hosios value $(\alpha=\beta=0.5)$ and present the outcomes in table 11 .

The equilibrium values of $\Omega_{L}$ (blue) and $\Omega_{H}$ (red) for different $\beta$ are plotted in the left panel of figure 10. The maximal value of $\Omega_{L}$ is achieved for $\beta=0.3$ and it is close to 0.3878 . Low-skilled workers search jobs in both submarkets and they gain more from the presence of high-skilled workers. Therefore, when bargaining power of workers are below than Hosios value, firms expect higher profits for high productivity submarket. On the one hand, more intensive job creation in the high productivity submarket encourages to create more jobs in the low productivity submarket. But on the other hand, low-skilled workers quit their first jobs more often, so it reduces the expected profits of low productivity firms and discourages job creation in the low productivity submarket. However, in our numerical example, the former effect dominates, so low-skilled workers obtain a higher level of welfare if the bargaining power is below than Hosios value.

In contrast, high-skilled workers search for jobs only in the high productivity firms and they obtain a higher value of welfare if the bargaining power is above the Hosios value. The maximal value of $\Omega_{H}$ is obtained for $\beta=0.65$ and it is close to 0.3159 . Therefore, the maximal value of total welfare $\Omega_{L}+\Omega_{H}$ is 0.700647 and is achieved for $\beta=0.51$, which is in between 0.3 and 0.65 and is slightly higher than $\alpha=0.5$ (black solid curve on the right panel of figure 10). This value is lower than 0.7224 which is the new total welfare level reached when the policy is implemented (dashed black line). Thus, it implies that the decentralized equilibrium is not constraint efficient for any value of $\beta$. The total welfare gain of the policy changes with $\beta$ and it is minimized at $\beta=0.51$. Meaning that $\Omega_{L}+\Omega_{H}$ is maximized at a bargaining power which is different than 
Hosios value.

Table 11: The values of policy instruments, $\Omega_{L}, \Omega_{H}$ and $\Omega_{L}+\Omega_{H}$ with and without policy for different values of $\beta$ in case of $y_{L}=1.25, y_{L H}=1.35$ and $y_{H}=1.45$

\begin{tabular}{lcccccc}
\hline \hline & $\beta=0.25$ & $\beta=0.3$ & $\beta=0.5$ & $\beta=0.51$ & $\beta=0.65$ & $\beta=0.7$ \\
$\tau_{L}$ & 0.0481 & 0.0571 & 0.0813 & 0.0821 & 0.0925 & 0.0955 \\
$\tau_{H}$ & 0.3167 & 0.2869 & 0.1078 & 0.0950 & -0.1607 & -0.3100 \\
$T$ & 0.0273 & 0.0263 & 0.0169 & 0.0162 & -0.00001 & -0.0098 \\
$\Omega_{L}$ without policy & 0.3876 & 0.3878 & 0.3860 & 0.3858 & 0.3834 & 0.3825 \\
$\Omega_{L}$ with policy & 0.3965 & 0.3981 & 0.4066 & 0.4072 & 0.4181 & 0.4244 \\
$\Omega_{H}$ without policy & 0.3085 & 0.3101 & 0.3146 & 0.3147 & 0.3159 & 0.3158 \\
$\Omega_{H}$ with policy & 0.3259 & 0.3243 & 0.3158 & 0.3152 & 0.3043 & 0.2980 \\
$\Omega_{L}+\Omega_{H}$ without policy & 0.6962 & 0.6979 & 0.700642 & 0.700647 & 0.6994 & 0.6983 \\
Net welfare gain (\%) & 3.6317 & 3.3906 & 3.0240 & 3.0234 & 3.1851 & 3.3399 \\
\hline \hline
\end{tabular}
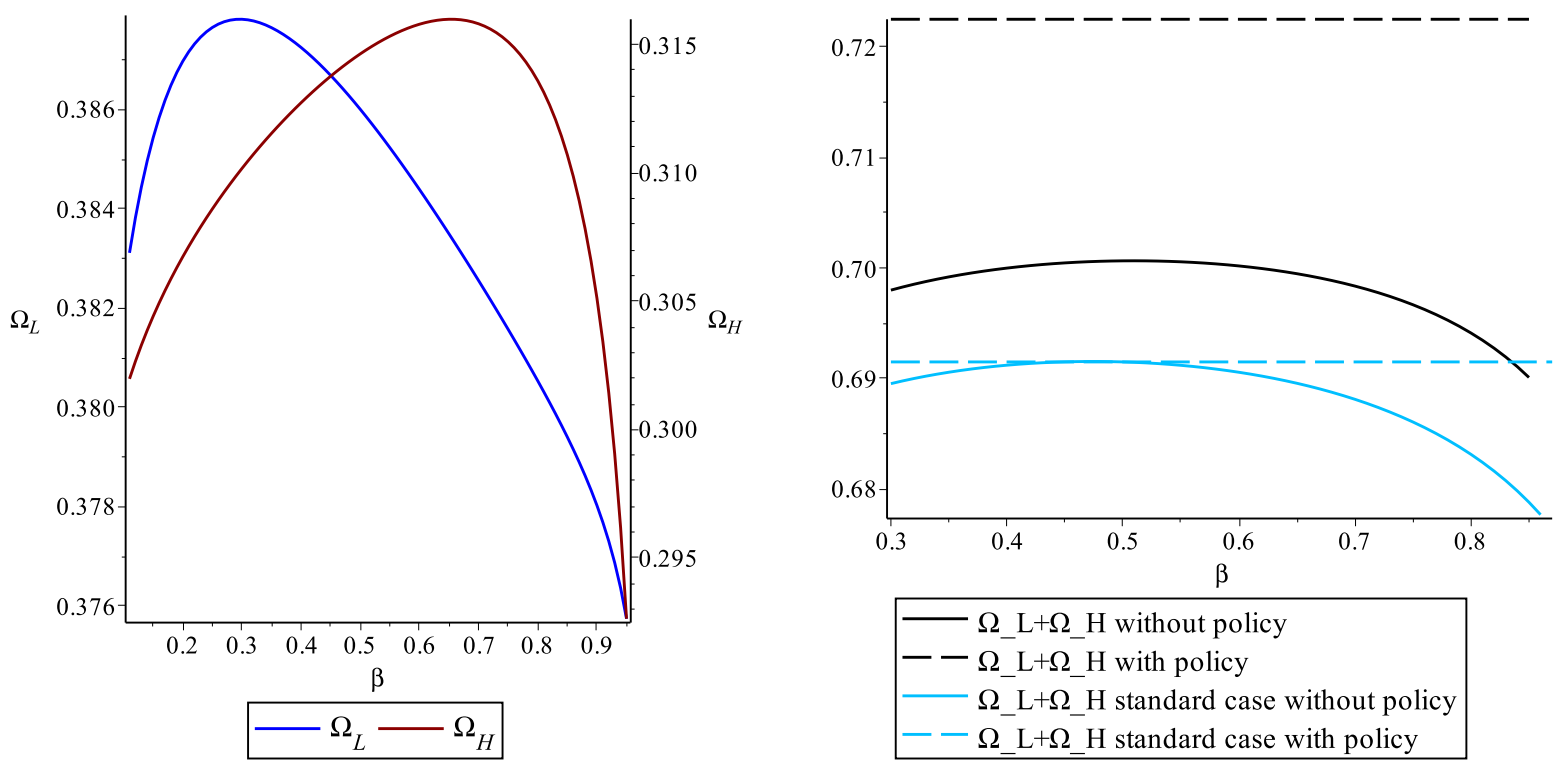

Figure 9: Left panel: $\Omega_{L}$ and $\Omega_{H}$. Right panel: total welfare $\Omega_{L}+\Omega_{H}$

Finally, we compare our benchmark economy versus the standard economy without take-itor-leave-it wage offer and on-the-job search activity by workers. All parameters are set the same as benchmark case. The blue solid curve on the right panel of figure 10 illustrates welfare in the decentralized equilibrium for standard economy, whereas the dashed blue line corresponds to the maximum welfare in the centralized economy. In this case, welfare in the standard economy is maximized for the Hosios value of the bargaining power $\beta=\alpha=0.5$. 


\section{Conclusion}

In this paper, we develop a search and matching model with heterogeneous workers, firms, and on-the-job search. Low-skilled workers are allowed to seek better paid jobs at high productivity firms while they are being employed. Low productivity firms make take-it-or-leave-it wage offers, while high productivity firms use Nash bargaining over wages. We prove the existence of a decentralized equilibrium and it is constraint inefficient for any value of bargaining power. There are two new sources of inefficiency in the model. First, low-skilled workers do not have any bargaining power when they are employed at low productivity firms. Hence the total job surplus is fully acquired by the firms, even though the social planner would give only a part of the total job surplus to the firms. This increases the number of vacancies and reduces the equilibrium unemployment rates of low-skilled workers below the socially efficient level. Second, there is pooling inefficiency which is due to search activity by both types of workers in the high productivity submarket. The inefficiency significantly reduces the reservation wages of low-skilled workers when the productivity difference in the two jobs for workers is increased. Lower wages are acceptable for the low-skilled workers as they expect to find better paid jobs at high productivity firms later. On the one hand, it encourages low productivity firms to create more vacancies even though low-skilled workers change their first jobs more frequently. On the other hand, high productivity firms create more vacancies since they expect high profits from higher labour supply by the experienced low-skilled workers. Therefore, the equilibrium wages are inefficiently low for low-skilled workers and inefficiently high for high-skilled workers. The effects are moderated when the productivity difference in the two jobs for low-skilled workers is small. We show that these inefficiencies can be internalized by type-specific lump-sum transfers paid to workers. The estimated net welfare gain is around $3.02 \%$.

Further, we analyze the effect of workers' skill composition variations on the labour market outcomes. Both types of firms may benefit from the increase in the supply of low-skilled workers driven by increasing productivity difference between the two jobs for low-skilled workers. When this productivity difference increases it is more beneficial for both types of firms, as a result they create more vacancies. Low productivity firms can gain higher profits since they offer lower wages to low-skilled workers. These workers are willing to accept lower wages in order to get experienced and seek better paid jobs in the future as well. Thus, the high productivity firms have incentive to hire experienced low-skilled workers by creating more vacancies. On the contrary, when the productivity difference is small, the effects are reversed. In this case, the reservation wages of low-skilled workers will not decrease dramatically since changing their jobs later is not as attractive as before. The bargained wages of high-skilled workers also will not increase as much as before due to the worse outside options. As a result, fewer vacancies are created by both types of firms.

Moreover, we find that wage dispersion among workers is larger when high-skilled workers are more productive and thus impose a positive externality on low-skilled workers. This result is different from the result obtained by Blazquez and Jansen (2008). The main reason is that one-the-job search activity by low-skilled workers reduces their reservation wages significantly by taking into account their expectation about changing their jobs to the high productivity firms. In the meantime, the bargained wages of high-skilled workers increase due to their better 
outside options. Thus, the wage gap among workers increases. The effect is stronger when the productivity difference in the two jobs for low-skilled workers is larger, in particular, the wage dispersion within the group increases significantly, and vice versa.

Finally, both types of firms emerge in the equilibrium when firms are allowed to open vacancies in both submarkets. This result opposes the findings obtained by Ellingsen and Rosen (2003), which argue that firms choose open vacancies only in the high productivity submarket. In our framework the main mechanism which differs is the on-the-job search activity by lowskilled workers, which affects the equilibrium wages of workers. On the one hand, it is attractive for firms to open vacancies in the low productivity submarket since they pay low wages to workers. On the other hand, it is also profitable for firms to open vacancies in the high productivity submarket because the probability of jobs being filled with low-skilled workers increases significantly even though the bargained wages of high-skilled workers increase. Therefore, both types of firms coexist in the equilibrium under the baseline parameters.

\section{Appendix}

\section{Appendix A}

Proof of Lemma 1. The unemployment and employment levels at the steady-state can be written as:

$$
\begin{aligned}
& e_{H}=\frac{\lambda\left(\theta_{H}\right)(1-\mu)}{\left(\delta_{H}+\lambda\left(\theta_{H}\right)\right)}, \quad u_{H}=\frac{(1-\mu) \delta_{H}}{\left(\delta_{H}+\lambda\left(\theta_{H}\right)\right)}, \quad u_{L}=\left[\frac{\delta_{H}\left(\delta_{L}+\lambda\left(\theta_{H}\right)\right)}{\delta_{H}\left(\delta_{L}+\lambda\left(\theta_{H}\right)\right)+\lambda\left(\theta_{L}\right)\left(\delta_{H}+\lambda\left(\theta_{H}\right)\right)}\right] \mu, \\
& e_{L L}=\left[\frac{\delta_{H} \lambda\left(\theta_{L}\right)}{\delta_{H}\left(\delta_{L}+\lambda\left(\theta_{H}\right)\right)+\lambda\left(\theta_{L}\right)\left(\delta_{H}+\lambda\left(\theta_{H}\right)\right)}\right] \mu, \quad e_{L H}=\left[\frac{\lambda\left(\theta_{H}\right) \lambda\left(\theta_{L}\right)}{\delta_{H}\left(\delta_{L}+\lambda\left(\theta_{H}\right)\right)+\lambda\left(\theta_{L}\right)\left(\delta_{H}+\lambda\left(\theta_{H}\right)\right)}\right] \mu .
\end{aligned}
$$

Thus, $\gamma\left(\theta_{L}, \theta_{H}\right)$ is expressed as:

$\gamma\left(\theta_{L}, \theta_{H}\right)=\frac{u_{H}}{\left(u_{H}+e_{L L}\right)}=\frac{(1-\mu) \delta_{H}}{\delta_{H}+\lambda\left(\theta_{H}\right)} /\left[\frac{(1-\mu) \delta_{H}}{\delta_{H}+\lambda\left(\theta_{H}\right)}+\frac{\delta_{H} \lambda\left(\theta_{L}\right) \mu}{\delta_{H}\left(\delta_{L}+\lambda\left(\theta_{H}\right)\right)+\lambda\left(\theta_{L}\right)\left(\delta_{H}+\lambda\left(\theta_{H}\right)\right)}\right]$.

Let us prove that $\gamma\left(\theta_{L}, \theta_{H}\right)$ is decreasing in $\theta_{L}$. Then it is enough to show that the denominator of $\gamma\left(\theta_{L}, \theta_{H}\right)$ is increasing in $\theta_{L}$. Denote the denominator by $D\left(\theta_{L}, \theta_{H}\right)$ :

$$
D\left(\theta_{L}, \theta_{H}\right) \equiv\left[\frac{(1-\mu) \delta_{H}}{\delta_{H}+\lambda\left(\theta_{H}\right)}+\frac{\delta_{H} \lambda\left(\theta_{L}\right) \mu}{\delta_{H}\left(\delta_{L}+\lambda\left(\theta_{H}\right)\right)+\lambda\left(\theta_{L}\right)\left(\delta_{H}+\lambda\left(\theta_{H}\right)\right)}\right],
$$

the first order derivative of of $D\left(\theta_{L}, \theta_{H}\right)$ with respect to $\theta_{L}$ can be written as:

$$
\begin{aligned}
\frac{\partial D\left(\theta_{L}, \theta_{H}\right)}{\partial \theta_{L}} & =\frac{\delta_{H} \mu \lambda^{\prime}\left(\theta_{L}\right)\left[\delta_{H}\left(\delta_{L}+\lambda\left(\theta_{H}\right)\right)+\lambda\left(\theta_{L}\right)\left(\delta_{H}+\lambda\left(\theta_{H}\right)\right)\right]-\delta_{H} \lambda\left(\theta_{L}\right) \mu \lambda^{\prime}\left(\theta_{L}\right)\left(\delta_{H}+\lambda\left(\theta_{H}\right)\right)}{\left[\delta_{H}\left(\delta_{L}+\lambda\left(\theta_{H}\right)\right)+\lambda\left(\theta_{L}\right)\left(\delta_{H}+\lambda\left(\theta_{H}\right)\right)\right]^{2}} \\
& =\frac{\delta_{H}^{2} \mu\left(\delta_{L}+\lambda\left(\theta_{H}\right)\right) \lambda^{\prime}\left(\theta_{L}\right)}{\left[\delta_{H}\left(\delta_{L}+\lambda\left(\theta_{H}\right)\right)+\lambda\left(\theta_{L}\right)\left(\delta_{H}+\lambda\left(\theta_{H}\right)\right)\right]^{2}}>0 .
\end{aligned}
$$

Next, we prove that $\gamma\left(\theta_{L}, \theta_{H}\right)$ is decreasing in $\theta_{H}$. The first order derivative of $\gamma\left(\theta_{L}, \theta_{H}\right)$ with 
respect to $\theta_{H}$ can be written as:

$$
\frac{\partial \gamma\left(\theta_{L}, \theta_{H}\right)}{\partial \theta_{H}}=\frac{\left(\frac{(1-\mu) \delta_{H}}{\delta_{H}+\lambda\left(\theta_{H}\right)}\right)_{\theta_{H}}^{\prime} D\left(\theta_{L}, \theta_{H}\right)-\left(\frac{(1-\mu) \delta_{H}}{\delta_{H}+\lambda\left(\theta_{H}\right)}\right) D_{\theta_{H}}^{\prime}\left(\theta_{L}, \theta_{H}\right)}{D\left(\theta_{L}, \theta_{H}\right)^{2}}=\frac{N\left(\theta_{L}, \theta_{H}\right)}{D\left(\theta_{L}, \theta_{H}\right)^{2}}
$$

where the nominator is denoted by $N\left(\theta_{L}, \theta_{H}\right)$ :

$$
\begin{aligned}
N\left(\theta_{L}, \theta_{H}\right) & =\left(\frac{(1-\mu) \delta_{H}}{\left(\delta_{H}+\lambda\left(\theta_{H}\right)\right)}\right)_{\theta_{H}}^{\prime}\left[\frac{\delta_{H} \lambda\left(\theta_{L}\right) \mu}{\left[\delta_{H}\left(\delta_{L}+\lambda\left(\theta_{H}\right)\right)+\lambda\left(\theta_{L}\right)\left(\delta_{H}+\lambda\left(\theta_{H}\right)\right)\right]}\right] \\
& -\frac{(1-\mu) \delta_{H}}{\left(\delta_{H}+\lambda\left(\theta_{H}\right)\right)}\left(\frac{\delta_{H} \lambda\left(\theta_{L}\right) \mu}{\left[\delta_{H}\left(\delta_{L}+\lambda\left(\theta_{H}\right)\right)+\lambda\left(\theta_{L}\right)\left(\delta_{H}+\lambda\left(\theta_{H}\right)\right)\right]}\right)_{\theta_{H}}^{\prime} \\
& =-\frac{(1-\mu) \delta_{H}^{2} \lambda\left(\theta_{L}\right) \mu \lambda^{\prime}\left(\theta_{H}\right)}{\left(\delta_{H}+\lambda\left(\theta_{H}\right)\right)\left[\delta_{H}\left(\delta_{L}+\lambda\left(\theta_{H}\right)\right)+\lambda\left(\theta_{L}\right)\left(\delta_{H}+\lambda\left(\theta_{H}\right)\right)\right]} \\
& \times\left[\frac{1}{\left(\delta_{H}+\lambda\left(\theta_{H}\right)\right)}-\frac{\left(\delta_{H}+\lambda\left(\theta_{L}\right)\right)}{\left[\delta_{H}\left(\delta_{L}+\lambda\left(\theta_{H}\right)\right)+\lambda\left(\theta_{L}\right)\left(\delta_{H}+\lambda\left(\theta_{H}\right)\right)\right]}\right] \\
& =-\frac{(1-\mu) \delta_{H}^{2} \lambda\left(\theta_{L}\right) \mu \lambda^{\prime}\left(\theta_{H}\right)}{\left(\delta_{H}+\lambda\left(\theta_{H}\right)\right)\left[\delta_{H}\left(\delta_{L}+\lambda\left(\theta_{H}\right)\right)+\lambda\left(\theta_{L}\right)\left(\delta_{H}+\lambda\left(\theta_{H}\right)\right)\right]} \\
& \times\left[\frac{\delta_{H}\left(\delta_{L}+\lambda\left(\theta_{H}\right)\right)+\lambda\left(\theta_{L}\right)\left(\delta_{H}+\lambda\left(\theta_{H}\right)\right)-\left(\delta_{H}+\lambda\left(\theta_{L}\right)\right)\left(\delta_{H}+\lambda\left(\theta_{H}\right)\right)}{\left(\delta_{H}+\lambda\left(\theta_{H}\right)\right)\left[\delta_{H}\left(\delta_{L}+\lambda\left(\theta_{H}\right)\right)+\lambda\left(\theta_{L}\right)\left(\delta_{H}+\lambda\left(\theta_{H}\right)\right)\right]}\right] \\
& =-\frac{(1-\mu) \delta_{H}^{2} \lambda\left(\theta_{L}\right) \mu \lambda^{\prime}\left(\theta_{H}\right) \delta_{H}\left(\delta_{L}-\delta_{H}\right)}{\left(\delta_{H}+\lambda\left(\theta_{H}\right)\right)^{2}\left[\delta_{H}\left(\delta_{L}+\lambda\left(\theta_{H}\right)\right)+\lambda\left(\theta_{L}\right)\left(\delta_{H}+\lambda\left(\theta_{H}\right)\right)\right]^{2}} .
\end{aligned}
$$

This yields:

$\frac{\partial \gamma\left(\theta_{L}, \theta_{H}\right)}{\partial \theta_{H}}=-\frac{(1-\mu) \delta_{H} \lambda^{\prime}\left(\theta_{H}\right) \mu \lambda\left(\theta_{L}\right)\left(\delta_{L}-\delta_{H}\right)}{\left[(1-\mu)\left[\delta_{H}\left(\delta_{L}+\lambda\left(\theta_{L}\right)\right)+\lambda\left(\theta_{L}\right)\left(\delta_{H}+\lambda\left(\theta_{H}\right)\right)\right]+\lambda\left(\theta_{L}\right) \mu\left(\delta_{H}+\lambda\left(\theta_{H}\right)\right)\right]^{2}}<0$.

Further, we compute the following limits of $\gamma\left(\theta_{L}, \theta_{H}\right)$ :

$$
\begin{aligned}
& \lim _{\theta_{L} \rightarrow 0} \gamma\left(\theta_{L}, \theta_{H}\right)=\lim _{\theta_{L} \rightarrow 0} \frac{\frac{(1-\mu) \delta_{H}}{\left(\delta_{H}+\lambda\left(\theta_{H}\right)\right)}}{\frac{(1-\mu) \delta_{H}}{\left(\delta_{H}+\lambda\left(\theta_{H}\right)\right)}+\frac{\delta_{H} \lambda\left(\theta_{L}\right) \mu}{\delta_{H}\left(\delta_{L}+\lambda\left(\theta_{H}\right)\right)+\lambda\left(\theta_{L}\right)\left(\delta_{H}+\lambda\left(\theta_{H}\right)\right)}}=1, \\
& \lim _{\theta_{L} \rightarrow \infty} \gamma\left(\theta_{L}, \theta_{H}\right)=\lim _{\theta_{L} \rightarrow \infty} \frac{\frac{(1-\mu) \delta_{H}}{\left(\delta_{H}+\lambda\left(\theta_{H}\right)\right)}}{\frac{\delta_{H} \lambda\left(\theta_{L}\right) \mu}{\left(\delta_{H}+\lambda\left(\theta_{H}\right)\right)}+\frac{\theta_{H}}{\delta_{H}\left(\delta_{L}+\lambda\left(\theta_{H}\right)\right)+\lambda\left(\theta_{L}\right)\left(\delta_{H}+\lambda\left(\theta_{H}\right)\right)}} \\
& =\frac{\frac{(1-\mu) \delta_{H}}{\left(\delta_{H}+\lambda\left(\theta_{H}\right)\right)}}{\frac{(1-\mu) \delta_{H}}{\left(\delta_{H}+\lambda\left(\theta_{H}\right)\right)}+\frac{\mu \delta_{H}}{\left(\delta_{H}+\lambda\left(\theta_{H}\right)\right)}}=(1-\mu) \text {, } \\
& \lim _{\theta_{H} \rightarrow 0} \gamma\left(\theta_{L}, \theta_{H}\right)=\frac{(1-\mu)}{(1-\mu)+\frac{\delta_{H} \lambda\left(\theta_{L}\right) \mu}{\delta_{H} \delta_{L}+\lambda\left(\theta_{L}\right) \delta_{H}}}=\frac{(1-\mu)}{\left[(1-\mu)+\lambda\left(\theta_{L}\right) \mu /\left(\delta_{L}+\lambda\left(\theta_{L}\right)\right)\right]},
\end{aligned}
$$




$$
\begin{aligned}
& \lim _{\theta_{H} \rightarrow \infty} \gamma\left(\theta_{L}, \theta_{H}\right)=\lim _{\theta_{H} \rightarrow \infty} \frac{\frac{(1-\mu) \delta_{H}}{\lambda\left(\theta_{H}\right)\left[\delta_{H} / \lambda\left(\theta_{H}\right)+1\right]}}{\frac{(1-\mu) \delta_{H}}{\lambda\left(\theta_{H}\right)\left[\delta_{H} / \lambda\left(\theta_{H}\right)+1\right]}+\frac{\delta_{H} \lambda\left(\theta_{L}\right) \mu}{\lambda\left(\theta_{H}\right)\left[\delta_{H}\left[\delta_{L} / \lambda\left(\theta_{L}\right)+1\right]+\lambda\left(\theta_{H}\right)\left[\delta_{H} / \lambda\left(\theta_{H}\right)+1\right]\right]}} \\
& =\frac{(1-\mu)}{\left[(1-\mu)+\lambda\left(\theta_{L}\right) \mu /\left(\delta_{H}+\lambda\left(\theta_{L}\right)\right)\right]} \text {. }
\end{aligned}
$$

Derivation of the bargained wages. Equation (4) can be rewritten as:

$$
J_{L}\left(y_{L}, w\right)-V=\frac{y_{L}-w-r V}{\left(r+\delta_{L}+\lambda\left(\theta_{H}\right)\right)}
$$

after substituting the left hand side of equation above into equation (6), we obtain the following:

$$
r V_{L}=\frac{-\left(r+\delta_{L}+\lambda\left(\theta_{H}\right)\right) c_{L}+q\left(\theta_{L}\right)\left(y_{L}-w-r V\right)}{\left(r+\delta_{L}+\lambda\left(\theta_{H}\right)\right)} .
$$

Equations (5) and (6) can be rewritten as:

$$
J_{L H}\left(y_{L H}, w\right)-V=\frac{y_{L H}-w-r V}{\left(r+\delta_{H}\right)}, \quad J_{H}\left(y_{H}, w\right)-V=\frac{y_{H}-w-r V}{\left(r+\delta_{H}\right)},
$$

similar, the expressions in equation (3) can be rewritten as follows:

$$
W_{L H}(w)-U_{L}=\frac{w-r U_{L}}{\left(r+\delta_{H}\right)}, \quad W_{H}(w)-U_{H}=\frac{w-r U_{H}}{\left(r+\delta_{H}\right)} .
$$

Consider the bargaining problem for low-skilled workers and high-productivity firms:

$$
\max _{w}\left(W_{L H}(w)-W_{L}\left(w_{L}^{*}\right)\right)^{\beta}\left(J_{L H}\left(y_{L H}, w\right)-V\right)^{1-\beta}
$$

Using $W_{L}\left(w_{L}^{*}\right)=U_{L}$ and equation (17), the first-order condition is written as:

$$
\begin{gathered}
\beta\left(w-r U_{L}\right)^{\beta-1}\left(y_{L H}-w-r V\right)^{1-\beta}+(1-\beta)\left(w-r U_{L}\right)^{\beta}\left(y_{L H}-w-r V\right)^{-\beta}(-1)=0 \text { or } \\
\beta\left(y_{L H}-w-r V\right)+(1-\beta)(-1)\left(w-r U_{L}\right)=0 .
\end{gathered}
$$

So the bargained wage for low-skilled workers $w_{L H}$ is obtained as:

$$
w_{L H}=\beta\left(y_{L H}-r V\right)+(1-\beta) r U_{L} .
$$

The bargaining problem for high-skilled workers and high-productivity firms:

$$
\max _{w}\left(W_{H}(w)-U_{H}\right)^{\beta}\left(J_{H}\left(y_{H}, w\right)-V\right)^{1-\beta}
$$


The first-order condition can be written as:

$$
\begin{gathered}
\beta\left(w-r U_{H}\right)^{\beta-1}\left(y_{H}-w-r V\right)^{1-\beta}+(1-\beta)\left(w-r U_{H}\right)^{\beta}\left(y_{H}-w-r V\right)^{-\beta}(-1)=0, \\
\beta\left(y_{H}-w-r V\right)+(1-\beta)(-1)\left(w-r U_{H}\right)=0 .
\end{gathered}
$$

Then, the bargained wage for high-skilled workers $w_{H}$ is obtained as:

$$
w_{H}=\beta\left(y_{H}-r V\right)+(1-\beta) r U_{H} .
$$

Derivation of the reservation wages. Evaluating equation (3) at $w_{L}^{*}$ and using the fact that $r U_{L}=z$ :

$$
r W_{L}\left(w_{L}^{*}\right)=w_{L}^{*}+\lambda\left(\theta_{H}\right)\left(W_{L H}\left(w_{L H}\right)-W_{L}\left(w_{L}^{*}\right)\right)-\delta_{L}\left(W_{L}\left(w_{L}^{*}\right)-U_{L}\right)
$$

which is equivalent to:

$$
r U_{L}=w_{L}^{*}+\lambda\left(\theta_{H}\right)\left(W_{L H}\left(w_{L H}\right)-U_{L}\right)
$$

where:

$$
W_{L H}\left(w_{L H}\right)-U_{L}=\frac{w_{L H}-r U_{L}}{\left(r+\delta_{H}\right)}=\frac{\beta\left(y_{L H}-r U_{L}-r V\right)}{\left(r+\delta_{H}\right)} .
$$

Using equations (18) and (19), we obtain the reservation wages for low-skilled workers as follows:

$$
w_{L}^{*}=z-\frac{\lambda\left(\theta_{H}\right) \beta\left(y_{L H}-z-r V\right)}{\left(r+\delta_{H}\right)} .
$$

Further, we obtain $r U_{H}=w_{H}^{*}$ by evaluating equation (3) at $w_{H}^{*}$. Equation (1) can be rewritten as:

$$
r U_{H}=z+\lambda\left(\theta_{H}\right)\left(\frac{w_{H}-r U_{H}}{r+\delta_{H}}\right),
$$

then expression for the bargained wage $w_{H}$ can be substituted into the above equation:

$$
\begin{aligned}
w_{H}^{*} & =z+\lambda\left(\theta_{H}\right)\left(\frac{\beta y_{H}+(1-\beta) r U_{H}-\beta r V-r U_{H}}{r+\delta_{H}}\right) \\
& =z+\frac{\beta \lambda\left(\theta_{H}\right)\left(y_{H}-r V\right)}{\left(r+\delta_{H}\right)}-\frac{\beta \lambda\left(\theta_{H}\right) w_{H}^{*}}{\left(r+\delta_{H}\right)} .
\end{aligned}
$$

Thus, the reservation wage for high-skilled workers $w_{H}^{*}$ is:

$$
w_{H}^{*}=\frac{z\left(r+\delta_{H}\right)+\lambda\left(\theta_{H}\right) \beta\left(y_{H}-r V\right)}{\left(r+\delta_{H}+\beta \lambda\left(\theta_{H}\right)\right)} .
$$




\section{Appendix B}

Proof of Proposition 1. The two job creation curves $\left(J C_{L}\right)$ and $\left(J C_{H}\right)$ can be rewritten as:

$$
\begin{gathered}
r V_{L}=-c_{L}+q\left(\theta_{L}\right) S_{L} \\
r V_{H}=-c_{H}+(1-\beta) q\left(\theta_{H}\right)\left((1-\gamma) S_{L H}+\gamma S_{H}\right)
\end{gathered}
$$

which implies that:

$\eta r V_{L}+(1-\eta) r V_{H}=\eta\left[-c_{L}+q\left(\theta_{L}\right) S_{L}\right]+(1-\eta)\left[-c_{H}+(1-\beta) q\left(\theta_{H}\right)\left((1-\gamma) S_{L H}+\gamma S_{H}\right)\right]$

which is equivalent to:

$$
\eta\left[q\left(\theta_{L}\right) S_{L}-\left(c_{L}+r K\right)\right]+(1-\eta)\left[(1-\beta) q\left(\theta_{H}\right)\left((1-\gamma) S_{L H}+\gamma S_{H}\right)-\left(c_{H}+r K\right)\right]=0 .
$$

where we use that the fact that $\eta\left(K-V_{L}\right)+(1-\eta)\left(K-V_{H}\right)=0$.

Proof of Proposition 2. The net profits of filled jobs for high productivity firms with low and high skilled workers become, respectively:

$$
\begin{gathered}
J_{L H}\left(y_{L H}, w_{L H}\right)-V=\frac{y_{L H}-w_{L H}-r V}{\left(r+\delta_{H}\right)}=\frac{(1-\beta)\left(y_{L H}-z-r V\right)}{\left(r+\delta_{H}\right)}, \\
J_{H}\left(y_{H}, w_{H}\right)-V=\frac{y_{H}-w_{H}-r V}{\left(r+\delta_{H}\right)}=\frac{(1-\beta)\left(y_{H}-z-r V\right)}{\left(r+\delta_{H}+\beta \lambda\left(\theta_{H}\right)\right)}
\end{gathered}
$$

The total job surplus in a match between a low productivity firm and a low-skilled worker $S_{L}=J_{L}-V_{L}+W_{L}-\left.U_{L}\right|_{w=w_{L}^{*}}$ can be written as:

$$
\begin{aligned}
S_{L} & =J_{L}\left(y_{L}, w_{L}^{*}\right)-V=\frac{y_{L}-w_{L}^{*}-r V}{\left(r+\delta_{L}+\lambda\left(\theta_{H}\right)\right)} \\
& =\frac{\left(y_{L}-z-r V\right)\left(r+\delta_{H}\right)+\lambda\left(\theta_{H}\right) \beta\left(y_{L H}-z-r V\right)}{\left(r+\delta_{H}\right)\left(r+\delta_{L}+\lambda\left(\theta_{H}\right)\right)},
\end{aligned}
$$

similar, the total job surplus in a match between a high productivity firm and a low-skilled worker is:

$$
\begin{aligned}
S_{L H} & =J_{L H}\left(y_{L H}, w_{L H}\right)-V+W_{L H}\left(w_{L H}\right)-U_{L} \\
& =\frac{(1-\beta)\left(y_{L H}-z-r V\right)}{\left(r+\delta_{H}\right)}+\frac{\beta\left(y_{L H}-z-r V\right)}{\left(r+\delta_{H}\right)}=\frac{\left(y_{L H}-z-r V\right)}{\left(r+\delta_{H}\right)} .
\end{aligned}
$$

The total job surplus in a match between a high productivity firm and a high-skilled worker can 
be written as:

$$
\begin{aligned}
S_{H} & =J_{H}\left(y_{H}, w_{H}\right)-V+W_{H}\left(w_{H}\right)-U_{H} \\
& =\frac{(1-\beta)\left(y_{H}-w_{H}^{*}-r V\right)}{\left(r+\delta_{H}\right)}+\frac{\beta\left(y_{H}-w_{H}^{*}-r V\right)}{\left(r+\delta_{H}\right)}=\frac{\left(y_{H}-z-r V\right)}{\left(r+\delta_{H}+\beta \lambda\left(\theta_{H}\right)\right)} .
\end{aligned}
$$

We can obtain two job creation curves $\left(J C_{L}\right)$ and $\left(J C_{H}\right)$ by substituting expressions for $S_{L}$, $S_{L H}$ and $S_{H}$ :

$$
\begin{gathered}
\frac{\left(c_{L}+r V_{L}\right)}{q\left(\theta_{L}\right)}=S_{L}=\frac{\left(y_{L}-z-r V\right)\left(r+\delta_{H}\right)+\lambda\left(\theta_{H}\right) \beta\left(y_{L H}-z-r V\right)}{\left(r+\delta_{H}\right)\left(r+\delta_{L}+\lambda\left(\theta_{H}\right)\right)}, \\
\frac{\left(c_{H}+r V_{H}\right)}{q\left(\theta_{H}\right)}=\left[\frac{e_{L L}}{e_{L L}+u_{H}}\left(J_{L H}\left(y_{L H}, w_{L H}\right)-V\right)+\frac{u_{H}}{e_{L L}+u_{H}}\left(J_{H}\left(y_{H}, w_{H}\right)-V\right)\right] \\
=(1-\beta)\left[\left[1-\gamma\left(\theta_{L}, \theta_{H}\right)\right] \frac{\left(y_{L H}-z-r V\right)}{\left(r+\delta_{H}\right)}+\gamma\left(\theta_{L}, \theta_{H}\right) \frac{\left(y_{H}-z-r V\right)}{\left(r+\delta_{H}+\beta \lambda\left(\theta_{H}\right)\right)}\right] \\
=(1-\beta)\left[\left[1-\gamma\left(\theta_{L}, \theta_{H}\right)\right] S_{L H}+\gamma\left(\theta_{L}, \theta_{H}\right) S_{H}\right],
\end{gathered}
$$

and these two expression complete the proof by using $V_{L}=V_{H}=V=K$.

Proof of Corollary 1. The first order derivative of $S_{L}$ with respect to $\theta_{H}$ is obtained as:

$$
\begin{aligned}
\frac{\partial S_{L}}{\partial \theta_{H}} & =\frac{\lambda^{\prime}\left(\theta_{H}\right) \beta\left(y_{L H}-z-r K\right)\left(r+\delta_{L}+\lambda\left(\theta_{H}\right)\right)}{\left(r+\delta_{H}\right)\left(r+\delta_{L}+\lambda\left(\theta_{H}\right)\right)^{2}} \\
& -\frac{\left[\left(y_{L}-z-r K\right)\left(r+\delta_{H}\right)+\lambda\left(\theta_{H}\right) \beta\left(y_{L H}-z-r K\right)\right] \lambda^{\prime}\left(\theta_{H}\right)}{\left(r+\delta_{H}\right)\left(r+\delta_{L}+\lambda\left(\theta_{H}\right)\right)^{2}} \\
& =\frac{\lambda^{\prime}\left(\theta_{H}\right)\left[\beta\left(y_{L H}-z-r K\right)\left(r+\delta_{L}\right)-\left(y_{L}-z-r K\right)\left(r+\delta_{H}\right)\right]}{\left(r+\delta_{L}\right)\left(r+\delta_{L}+\lambda\left(\theta_{H}\right)\right)^{2}},
\end{aligned}
$$

define the productivity threshold $y_{L}^{*}$ as follows:

$$
y_{L}^{*} \equiv \frac{\beta\left(y_{L H}-z-r K\right)\left(r+\delta_{L}\right)}{\left(r+\delta_{H}\right)}+z+r K .
$$

Then, the job surplus $S_{L}$ can be either increasing or decreasing function in $\theta_{H}$ :

$$
\left\{\begin{array}{lll}
\frac{\partial S_{L}}{\partial \theta_{H}}>0 & \text { if } & y_{L}<y_{L}^{*} \\
\frac{\partial S_{L}}{\partial \theta_{H}}<0 & \text { if } & y_{L}>y_{L}^{*}
\end{array}\right.
$$

Moreover, the curves $\left(J C_{L}\right)$ and $\left(J C_{H}\right)$ imply the lower and the upper bounds for $\theta_{L}$ and $\theta_{H}$ as follows:

Case 1 . Let $y_{L}<y_{L}^{*}$. Then, $\left(J C_{L}\right)$ implies a positive relationship between $\theta_{L}$ and $\theta_{H}$. The lower bound $\theta_{L}$ is determined by:

$$
\frac{\left(c_{L}+r K\right)}{q\left(\theta_{L}\right)}=\lim _{\theta_{H} \rightarrow 0} S_{L}=\frac{\left(y_{L}-z-r K\right)}{\left(r+\delta_{L}\right)},
$$


similar, the upper bound $\overline{\theta_{L}}$ is determined by:

$$
\frac{\left(c_{L}+r K\right)}{q\left(\theta_{L}\right)}=\lim _{\theta_{H} \rightarrow \infty} S_{L}=\lim _{\theta_{H} \rightarrow \infty} \frac{\frac{\left(y_{L}-z-r K\right)\left(r+\delta_{H}\right)}{\lambda\left(\theta_{H}\right)}+\beta\left(y_{L H}-z-r K\right)}{\frac{\left(r+\delta_{H}\right)\left(r+\delta_{L}\right)}{\lambda\left(\theta_{H}\right)}+r+\delta_{H}}=\frac{\beta\left(y_{L H}-z-r K\right)}{\left(r+\delta_{H}\right)} .
$$

Case 2. Let $y_{L}>y_{L}^{*}$. In this case, the curve $\left(J C_{L}\right)$ implies a negative relationship between $\theta_{L}$ and $\theta_{H}$. The lower bound $\theta_{L}$ is determined by:

$$
\frac{\left(c_{L}+r K\right)}{q\left(\theta_{L}\right)}=\lim _{\theta_{H} \rightarrow \infty} S_{L}=\frac{\beta\left(y_{L H}-z-r K\right)}{\left(r+\delta_{H}\right)} .
$$

Likewise, the upper bound $\overline{\theta_{L}}$ is determined by:

$$
\frac{\left(c_{L}+r K\right)}{q\left(\theta_{L}\right)}=\lim _{\theta_{H} \rightarrow 0} S_{L}=\frac{\left(y_{L}-z-r K\right)}{\left(r+\delta_{L}\right)} .
$$

Next, denote the expected profits of high productivity firms by $E P\left(\theta_{L}, \theta_{H}\right): E P\left(\theta_{L}, \theta_{H}\right) \equiv$ $(1-\beta)\left[1-\gamma\left(\theta_{L}, \theta_{H}\right) S_{L H}+\gamma\left(\theta_{L}, \theta_{H}\right) S_{H}\right]$. Using $\lim _{\theta_{L} \rightarrow 0} \gamma=1$, the curve $\left(J C_{H}\right)$ implies the lower bound $\underline{\theta_{H}}$ :

$$
\frac{\left(c_{H}+r K\right)}{q\left(\theta_{H}\right)}=\lim _{\theta_{L} \rightarrow 0} E P\left(\theta_{L}, \theta_{H}\right)=\frac{(1-\beta)\left(y_{H}-z-r K\right)}{\left(r+\delta_{H}+\beta \lambda\left(\theta_{H}\right)\right)},
$$

likewise, using $\lim _{\theta_{L} \rightarrow \infty} \gamma=(1-\mu)$, the upper bound $\overline{\theta_{H}}$ is determined as follows:

$$
\frac{\left(c_{H}+r K\right)}{q\left(\theta_{H}\right)}=\lim _{\theta_{L} \rightarrow \infty} E P\left(\theta_{L}, \theta_{H}\right)=(1-\beta)\left[\frac{\mu\left(y_{L H}-z-r K\right)}{\left(r+\delta_{H}\right)}+\frac{(1-\mu)\left(y_{H}-z-r K\right)}{\left(r+\delta_{H}+\beta \lambda\left(\theta_{H}\right)\right)}\right] .
$$

Proof of lemma 2. To show that $w_{H}^{*}>z$ is enough to prove that $w_{H}>w_{L H}$. It is true since $w_{H}^{*}$ is a linear combination of $\left(y_{H}-r V\right)$ and $z$.

Next, let us show that $w_{L H}>w_{L}^{*}$, which is equivalent to:

$$
\begin{gathered}
\beta y_{L H}+(1-\beta) z-\beta r V>z-\frac{\lambda\left(\theta_{H}\right) \beta\left(y_{L H}-z-r V\right)}{\left(r+\delta_{H}\right)} \\
\left(r+\delta_{H}\right) \beta y_{L H}+\left(r+\delta_{H}\right)(1-\beta) z-\left(r+\delta_{H}\right) \beta r V>z\left(r+\delta_{H}\right)-\lambda\left(\theta_{H}\right) \beta\left(y_{L H}-z-r V\right), \\
\beta\left(r+\delta_{H}+\lambda\left(\theta_{H}\right)\right)\left(y_{L H}-z\right)>\beta\left(r+\delta_{H}+\lambda\left(\theta_{H}\right)\right) r V \\
\left(y_{L H}-z\right)>r V .
\end{gathered}
$$

Finally, we show that $w_{H}>w_{H}^{*}$, which is equivalent to:

$$
\left(y_{H}-r V\right)>w_{H}^{*},
$$




$$
\begin{gathered}
\left(y_{H}-r V\right)>\frac{z\left(r+\delta_{H}\right)+\lambda\left(\theta_{H}\right) \beta\left(y_{H}-r V\right)}{\left(r+\delta_{H}+\lambda\left(\theta_{H}\right)\right)}, \\
\left(r+\delta_{H}\right)\left(y_{H}-r V\right)+\lambda\left(\theta_{H}\right) \beta\left(y_{H}-r V\right)>z\left(r+\delta_{H}\right)+\lambda\left(\theta_{H}\right) \beta\left(y_{H}-r V\right), \\
\left(y_{H}-z\right)>r V .
\end{gathered}
$$

\section{Appendix C}

Proof of Proposition 3. Given $e_{L L}=\mu-u_{L}-e_{L H}$ and $e_{H}=1-\mu-u_{H}$, the current value of Hamiltonian for the social planner problem becomes:

$$
\begin{aligned}
H & =z\left(u_{L}+u_{H}\right)+\left(\mu-u_{L}-e_{L H}\right)\left(y_{L}-r V_{L}\right)+e_{L H}\left(y_{L H}-r V_{H}\right)+\left(1-\mu-u_{H}\right)\left(y_{H}-r V_{H}\right) \\
& -\theta_{L} u_{L}\left(c_{L}+r K\right)-\theta_{H}\left(u_{H}+\mu-u_{L}-e_{L H}\right)\left(c_{H}+r K\right) \\
& +\phi_{u_{L}}\left[\lambda\left(\theta_{L}\right) u_{L}-\delta_{L}\left(\mu-u_{L}-e_{L H}\right)-\delta_{H} e_{L H}\right]+\phi_{u_{H}}\left[\lambda\left(\theta_{H}\right) u_{H}-\delta_{H}\left(1-\mu-u_{H}\right)\right] \\
& +\phi_{e_{L H}}\left[\lambda\left(\theta_{H}\right)\left(\mu-u_{L}-e_{L H}\right)-\delta_{H} e_{L H}\right]
\end{aligned}
$$

where $\phi_{u_{L}}, \phi_{u_{H}}$ and $\phi_{e_{L H}}$ are costate variables corresponding to $u_{L}, u_{H}$ and $e_{L H}$ respectively. Note that $\theta_{L}=\frac{\eta v}{u_{L}}, \theta_{H}=\frac{(1-\eta) v}{\left(u_{H}+e_{L L}\right)}, \lambda\left(\theta_{L}\right)=m_{0} \theta_{L}^{1-\alpha}$ and $\lambda\left(\theta_{H}\right)=m_{0} \theta_{H}^{1-\alpha}$. Then the first order conditions are given by:

$$
\begin{aligned}
\frac{\partial H}{\partial v} & =-u_{L}\left(c_{L}+r K\right) \frac{\partial \theta_{L}}{\partial v}-\left(u_{H}+\mu-u_{L}-e_{L H}\right)\left(c_{H}+r K\right) \frac{\partial \theta_{H}}{\partial v}+\phi_{u_{L}}(1-\alpha) q\left(\theta_{L}\right) u_{L} \frac{\partial \theta_{L}}{\partial v} \\
& +\phi_{u_{H}}(1-\alpha) q\left(\theta_{H}\right) u_{H} \frac{\partial \theta_{H}}{\partial v}+\phi_{e_{L H}}(1-\alpha) q\left(\theta_{H}\right)\left(\mu-u_{L}-e_{L H}\right) \frac{\partial \theta_{H}}{\partial v}=0 .
\end{aligned}
$$

Given that $\frac{\partial \theta_{i}}{\partial v} v=\theta_{i}, \lambda^{\prime}\left(\theta_{i}\right)=(1-\alpha) q\left(\theta_{i}\right)$ and $\theta_{i} q\left(\theta_{i}\right)=\lambda\left(\theta_{i}\right)(i=L, H)$, we get:

$$
\begin{aligned}
u_{L}\left[\phi_{u_{L}}(1-\alpha) \lambda\left(\theta_{L}\right)-\theta_{L}\left(c_{L}+r K\right)\right]+\left(u_{H}\right. & \left.+e_{L L}\right)\left[\phi_{u_{H}}(1-\alpha) \lambda\left(\theta_{H}\right) \gamma+\right. \\
& \left.+\phi_{e_{L H}}(1-\alpha) \lambda\left(\theta_{H}\right)(1-\gamma)-\theta_{H}\left(c_{H}+r K\right)\right]=0,
\end{aligned}
$$

which is equivalent to:

$$
\begin{aligned}
\eta\left[(1-\alpha) q\left(\theta_{L}\right) \phi_{u_{L}}-\left(c_{L}+r K\right)\right]+(1-\eta)\left[(1-\alpha) q\left(\theta_{H}\right) \gamma \phi_{u_{H}}+\right. & \\
& \left.+(1-\alpha) q\left(\theta_{H}\right)(1-\gamma) \phi_{e_{L H}}-\left(c_{H}+r K\right)\right]=0,
\end{aligned}
$$

Next we differentiate $H$ with respect to $u_{L}, u_{H}$ and $e_{L H}$, respectively:

$$
\begin{aligned}
\frac{\partial H}{\partial u_{L}} & =z-\left(y_{L}-r K\right)-\frac{\partial \theta_{L}}{\partial u_{L}} u_{L}\left(c_{L}+r K\right)-\theta_{L}\left(c_{L}+r K\right)+\theta_{H}\left(c_{H}+r K\right) \\
& +\phi_{u_{L}}\left[\lambda^{\prime}\left(\theta_{L}\right) \frac{\partial \theta_{L}}{\partial u_{L}} u_{L}+\lambda\left(\theta_{L}\right)+\delta_{L}\right]-\phi_{e_{L H}} \lambda\left(\theta_{H}\right)=-r \phi_{u_{L}}
\end{aligned}
$$




$$
\begin{gathered}
\frac{\partial H}{\partial u_{H}}=z-\left(y_{H}-r K\right)-\frac{\partial \theta_{H}}{\partial u_{H}}\left(u_{H}+\mu-u_{L}-e_{L H}\right)\left(c_{H}+r K\right)-\theta_{H}\left(c_{H}+r K\right) \\
+\phi_{u_{H}}\left[\lambda^{\prime}\left(\theta_{H}\right) \frac{\partial H}{\partial u_{H}} u_{H}+\lambda\left(\theta_{H}\right)+\delta_{H}\right]+\phi_{e_{L H}} \lambda^{\prime}\left(\theta_{H}\right) \frac{\partial \theta_{H}}{\partial u_{H}}\left(\mu-u_{L}-e_{L H}\right)=-r \phi_{u_{H}} \\
\frac{\partial H}{\partial e_{L H}}=-y_{L}+y_{L H}-\frac{\partial \theta_{H}}{\partial e_{L H}}\left(u_{H}+\mu-u_{L}-e_{L H}\right)\left(c_{H}+r K\right) \\
+\theta_{H}\left(c_{H}+r K\right)+\phi_{u_{L}}\left(\delta_{L}-\delta_{H}\right)+\phi_{u_{H}} \lambda^{\prime}\left(\theta_{H}\right) \frac{\partial \theta_{H}}{\partial e_{L H}} u_{H} \\
+\phi_{e_{L H}}\left[\lambda^{\prime}\left(\theta_{H}\right) \frac{\partial \theta_{H}}{\partial e_{L H}}\left(\mu-u_{L}-e_{L H}\right)-\lambda\left(\theta_{H}\right)-\delta_{H}\right]=r \phi_{e_{L H}} .
\end{gathered}
$$

Note that $u_{i} \frac{\partial \theta_{i}}{\partial u_{i}}=-\theta_{i}(i=L, H)$ and $e_{L H} \frac{\partial \theta_{H}}{\partial e_{L H}}=\theta_{H}$, and above three equations can be rewritten as follows:

$$
\begin{gathered}
\phi_{u_{L}}=\frac{y_{L}-z-r K-\theta_{H}\left(c_{H}+r K\right)+\lambda\left(\theta_{H}\right) \phi_{e_{L H}}}{\left(r+\delta_{L}+\alpha \lambda\left(\theta_{L}\right)\right)}, \\
\phi_{u_{H}}=\frac{y_{H}-z-r K+(1-\alpha) \lambda\left(\theta_{H}\right)(1-\gamma) \phi_{e_{L H}}}{\left(r+\delta_{H}+\alpha \lambda\left(\theta_{H}\right)\right)}, \\
\phi_{e_{L H}}=\frac{y_{L H}-y_{L}+\left(\delta_{L}-\delta_{H}\right) \phi_{u_{L}}+(1-\alpha) \gamma \lambda\left(\theta_{H}\right) \phi_{u_{H}}}{\left(r+\delta_{H}+(1-(1-\gamma)(1-\alpha)) \lambda\left(\theta_{H}\right)\right)} .
\end{gathered}
$$

Finally, the endogenous variables $\left\{u_{L}, u_{H}, e_{L H}, v\right\}$ are determined by the first-order conditions and it enables to compute the equilibrium market tightnesses for given $\eta$ as follows:

$$
\theta_{L}=\frac{v_{L}}{u_{L}}=\frac{\eta v}{u_{L}}, \quad \theta_{H}=\frac{v_{H}}{\left(u_{H}+e_{L L}\right)}=\frac{(1-\eta) v}{\left(u_{H}+e_{L L}\right)} .
$$

Proof of Proposition 4. The social planner maximizes equation (15) subject to the dynamics of unemployment and employment $\dot{u}_{L}=\delta_{L} e_{L L}+\delta_{H} e_{L H}-\lambda\left(\theta_{L}\right) u_{L}, u_{H}=\delta_{H} e_{H}-\lambda\left(\theta_{H}\right) u_{H}$ and $e_{\dot{L} H}=\lambda\left(\theta_{H}\right) e_{L L}-\delta_{H} e_{L H}$. Let $\phi_{u_{L}}, \phi_{u_{H}}$ and $\phi_{e_{L H}}$ be costate variables corresponding to $u_{L}, u_{H}$ and $e_{L H}$ respectively. The current value of Hamiltonian for the social planner problem can be written as:

$$
\begin{aligned}
H & =z\left(u_{L}+u_{H}\right)+\left(\mu-u_{L}-e_{L H}\right)\left(y_{L}-r K\right)+e_{L H}\left(y_{L H}-r K\right)+\left(1-\mu-u_{H}\right)\left(y_{H}-r K\right) \\
& -\theta_{L} u_{L}\left(c_{L}+r K\right)-\theta_{H}\left(u_{H}+\mu-u_{L}-e_{L H}\right)\left(c_{H}+r K\right) \\
& +\phi_{u_{L}}\left[\lambda\left(\theta_{L}\right) u_{L}-\delta_{L}\left(\mu-u_{L}-e_{L H}\right)-\delta_{H} e_{L H}\right]+\phi_{u_{H}}\left[\lambda\left(\theta_{H}\right) u_{H}-\delta_{H}\left(1-\mu-u_{H}\right)\right] \\
& +\phi_{e_{L H}}\left[\lambda\left(\theta_{H}\right)\left(\mu-u_{L}-e_{L H}\right)-\delta_{H} e_{L H}\right] .
\end{aligned}
$$


The first order conditions are given by:

$$
\begin{array}{r}
\frac{\partial H}{\partial \theta_{L}}=-u_{L}\left(c_{L}+r K\right)+\phi_{u_{L}} \lambda^{\prime}\left(\theta_{L}\right) u_{L}=0, \\
\frac{\partial H}{\partial \theta_{H}}=-\left(u_{H}+\mu-u_{L}-e_{L H}\right)\left(c_{H}+r K\right)+\phi_{u_{H}} \lambda^{\prime}\left(\theta_{H}\right) u_{H}+\phi_{e_{L H}} \lambda^{\prime}\left(\theta_{H}\right)\left(\mu-u_{L}-e_{L H}\right)=0 .
\end{array}
$$

Given that $\lambda^{\prime}\left(\theta_{i}\right)=(1-\alpha) q\left(\theta_{i}\right)=(1-\alpha) \lambda\left(\theta_{i}\right) / \theta_{i},(i=L, H)$, and $e_{L L}=\mu-u_{L}-e_{L H}$, $e_{H}=1-\mu-u_{H}$ and $\gamma=u_{H} /\left(u_{H}+e_{L L}\right)$ these two conditions can be rewritten as:

$$
\frac{\left(c_{L}+r K\right)}{q\left(\theta_{L}\right)}=(1-\alpha) \phi_{u_{L}}, \quad \frac{\left(c_{H}+r K\right)}{q\left(\theta_{H}\right)}=(1-\alpha)\left[(1-\gamma) \phi_{e_{L H}}+\gamma \phi_{u_{H}}\right] .
$$

Differentiating $H$ with respect to $u_{L}$ :

$$
\frac{\partial H}{\partial u_{L}}=z-\left(y_{L}-r K\right)-\theta_{1}\left(c_{L}+r K\right)+\theta_{H}\left(c_{H}+r K\right)+\phi_{u_{L}}\left(\lambda\left(\theta_{L}\right)+\delta_{L}\right)-\phi_{e_{L H}} \lambda\left(\theta_{H}\right)=-r \phi_{u_{L}}
$$

After combining equations (20) and (21), and rearrangement:

$$
\phi_{u_{L}}\left(r+\delta_{L}+\alpha \lambda\left(\theta_{L}\right)\right)=\left(y_{L}-z-r K\right)-\left(\gamma \phi_{u_{H}}+(1-\gamma) \phi_{e_{L H}}\right)(1-\alpha) \lambda\left(\theta_{H}\right)+\phi_{e_{L H}} \lambda\left(\theta_{H}\right) .
$$

Thus, $\phi_{u_{L}}$ is obtained as:

$$
\phi_{u_{L}}=\frac{\left(y_{L}-z-r K\right)-\gamma(1-\alpha) \lambda\left(\theta_{H}\right) \Delta \phi+\alpha \lambda\left(\theta_{H}\right) \phi_{e_{L H}}}{\left(r+\delta_{L}+\alpha \lambda\left(\theta_{L}\right)\right)}, \text { where } \quad \Delta \phi=\phi_{u_{H}}-\phi_{e_{L H}}
$$

Next we differentiate $H$ with respect to $u_{H}$ :

$$
\frac{\partial H}{\partial u_{H}}=z-\left(y_{H}-r K\right)-\theta_{H}\left(c_{H}+r K\right)+\phi_{u_{H}}\left(\lambda\left(\theta_{H}\right)+\delta_{H}\right)=-r \phi_{u_{H}} .
$$

After combining equations (20) and (21):

$$
z-\left(y_{H}-r K\right)-(1-\alpha) \lambda\left(\theta_{H}\right)\left(\gamma \phi_{u_{H}}+(1-\gamma) \phi_{e_{L H}}\right)=-\phi_{u_{H}}\left(r+\lambda\left(\theta_{H}\right)+\delta_{H}\right) .
$$

Thus,

$$
\phi_{u_{H}}=\frac{y_{H}-z-r K-(1-\alpha) \lambda\left(\theta_{H}\right)(1-\gamma) \Delta \phi}{\left(r+\delta_{H}+\alpha \lambda\left(\theta_{H}\right)\right)} .
$$

Differentiating $H$ with respect to $e_{L H}$ :

$$
\frac{\partial H}{\partial e_{L H}}=-\left(y_{L}-r K\right)+\left(y_{L H}-r K\right)+\theta_{H}\left(c_{H}+r K\right)+\phi_{u_{L}}\left(\delta_{L}-\delta_{H}\right)-\phi_{e_{L H}}\left(\lambda\left(\theta_{H}\right)+\delta_{H}\right)=r \phi_{e_{L H}}
$$

After combining equations (20) and (23):

$$
\begin{array}{r}
y_{L H}-y_{L}+(1-\alpha) \lambda\left(\theta_{H}\right)\left(\gamma \phi_{u_{H}}+(1-\gamma) \phi_{e_{L H}}\right)+\phi_{u_{L}}\left(\delta_{L}-\delta_{H}\right)= \\
=\phi_{e_{L H}}\left(r+\delta_{H}+\lambda\left(\theta_{H}\right)\right) .
\end{array}
$$


This yields:

$$
\phi_{e_{L H}}=\frac{y_{L H}-y_{L}+(1-\alpha) \lambda\left(\theta_{H}\right) \gamma \Delta \phi+\phi_{u_{L}}\left(\delta_{L}-\delta_{H}\right)}{\left(r+\delta_{H}+\alpha \lambda\left(\theta_{H}\right)\right)} .
$$

Note that the endogenous variables $\left\{\theta_{L}, \theta_{H}, u_{L}, u_{H}, e_{L H}\right\}$ are determined by these first-order conditions. Given $\frac{\eta}{1-\eta}=\frac{\eta v}{(1-\eta) v}=\frac{\theta_{L} u_{L}}{\theta_{H}\left(u_{H}+e_{L L}\right)}, \eta$ can be computed indirectly.

Proof of Proposition 5. Let us denote by the total job surpluses $S_{L}^{*}, S_{L H}^{*}$ and $S_{H}^{*}$ when the policy instruments $\left\{\tau_{L}, \tau_{H}, T\right\}$ are considered. The total job surplus of a match between a low-skilled worker and a high productivity firm, and a high-skilled worker and a high productivity firm can be written as:

$$
S_{L H}^{*}=\frac{y_{L H}-z-\tau_{L}-r K}{\left(r+\delta_{H}\right)} \quad \text { and } \quad S_{H}^{*}=\frac{y_{H}-z-\tau_{H}-r K}{r+\delta_{H}+\beta \lambda\left(\theta_{H}\right)},
$$

similar, the total job surplus of a match between a low-skilled worker and a low productivity firm is given by:

$$
S_{L}^{*}=\frac{\left(y_{L}-z-\tau_{L}-r K\right)\left(r+\delta_{H}\right)+\lambda\left(\theta_{H}\right) \beta\left(y_{L H}-z-\tau_{L}-r K\right)}{\left(r+\delta_{H}\right)\left(r+\delta_{L}+\lambda\left(\theta_{H}\right)\right)} .
$$

The job creation conditions in the low and high productivity submarkets become, respectively:

$$
\frac{\left(c_{L}+r K\right)}{q\left(\theta_{L}\right)}=S_{L}^{*}
$$

and

$$
\frac{\left(c_{H}+r K\right)}{q\left(\theta_{H}\right)}=(1-\beta)\left[(1-\gamma) S_{L H}^{*}+\gamma S_{H}^{*}\right] .
$$

Let Hosios condition hold. Since we evaluate all endogenous variables at socially optimal allocations, these conditions must satisfy:

$$
\begin{gathered}
(1-\beta) \phi_{u_{L}}=S_{L}^{*}, \\
(1-\beta)\left[(1-\gamma) \phi_{e_{L H}}+\gamma \phi_{u_{H}}\right]=(1-\beta)\left[(1-\gamma) S_{L H}^{*}+\gamma S_{H}^{*}\right] .
\end{gathered}
$$

The relationships between total job surpluses with and without policy instruments are given:

$$
\begin{gathered}
S_{L}^{*}=S_{L}-\frac{r+\delta_{H}+\beta \lambda\left(\theta_{H}\right)}{\left(r+\delta_{H}\right)\left(r+\delta_{L}+\lambda\left(\theta_{H}\right)\right)} \tau_{L}, \\
(1-\gamma) S_{L H}^{*}+\gamma S_{H}^{*}=(1-\gamma) S_{L H}+\gamma S_{H}-\frac{(1-\gamma)}{\left(r+\delta_{H}\right)} \tau_{L}-\frac{\gamma}{\left(r+\delta_{H}+\beta \lambda\left(\theta_{H}\right)\right)} \tau_{H} .
\end{gathered}
$$

Thus, $\tau_{L}$ and $\tau_{H}$ are obtained by using two equations above:

$$
\tau_{L}=\frac{\left(r+\delta_{H}\right)\left(r+\delta_{L}+\lambda\left(\theta_{H}\right)\right)}{\left(r+\delta_{H}+\beta \lambda\left(\theta_{H}\right)\right)}\left(S_{L}-(1-\beta) \phi_{u_{L}}\right),
$$




$$
\begin{array}{r}
\tau_{L}=\frac{\left(r+\delta_{H}+\beta \lambda\left(\theta_{H}\right)\right)}{\gamma}\left[(1-\gamma) S_{L H}+\gamma S_{H}-(1-\gamma) \phi_{e_{L H}}-\gamma \phi_{u_{H}}\right] \\
-\frac{(1-\gamma)}{\gamma}\left(r+\delta_{L}+\lambda\left(\theta_{H}\right)\right)\left(S_{L}-(1-\beta) \phi_{u_{L}}\right) .
\end{array}
$$

Finally, the transfer $T$ is computed to satisfy the budget balance: $u_{L} \tau_{L}+u_{H} \tau_{H}=T$.

\section{References}

ACEMOGLU D. (1999): "Changes in Unemployment and Wage Inequality: An Alternative Theory and Some Evidence", American Economic Review, 89: 1259-1278.

ALBRECHT J., L. NAVARRO, S. VROMAN (2010): "Efficiency in a Search and Matching Model with Endogenous Participation", Economics Letters, 106: 48-50.

ALBRECHT J., S. VROMAN (2002): "A Matching Model with Endogenous Skill Requirements", International Economic Review, 43: 283-305.

BLAZQUEZ M.T., M. JANSEN (2008): "Search, Mismatch and Unemployment", European Economic Review, 52: 498-526.

BONTEMPS C., J.M. ROBIN, G. J. VAN DEN BERG (1999): "An Empirical Equilibrium Job Search Model with Search on the Job and Heterogeneous Workers and Firms", International Economic Review, 40(4): 1039-1074.

BRENZEL H., H. GARTNER, C. SCHNABEL (2014): "Wage Posting or Wage Bargaining? Evidence from the Employers' Side", Labour Economics, 29: 41-48.

CAHUC P., F. FONTAINE (2009): "On the Efficiency of Job Search with Social Networks", Journal of Public Economic Theory, 11: 411-439.

DAMDINSUREN E., A. ZAHARIEVA (2018): "Expectation Formation and Learning in the Labour Market with On-the-Job Search and Nash Bargaining", Bielefeld University Working Papers in Economics and Management, Vol 12-2018.

DEL BONO E., D. VURI (2011): "Job Mobility and the Gender Wage Gap in Italy", Labour Economics, 18: 130-142.

DOLADO J.J., M. JANSEN, J.F. JIMENO (2008): "On the Job Search in a Matching Model with Heterogeneous Jobs and Workers", Bank of Spain Working Paper, 0813.

DUSTMANN C., C. MEGHIR (2005): "Wages, Experience and Seniority", Review of Economic Studies, 72: 77-108.

ELLINGSEN T., A. ROSEN (2003): "Fixed or flexible? Wage Setting in Search Equilibrium", Economica, 70: 233-250.

FLINN C. (2010): "The Minimum Wage and Labor Market Outcomes", MIT Press, Cambridge MA.

FLINN C., J. MABLI, J.MULLINS (2017): "Firms' Choices of Wage-Setting Protocols in the Presence of Minimum Wages", IRP Discussion Paper, 1434-17.

FONTAINE F. (2008a): "Do Workers Really Benefit from Their Social Networks?", Louvain Economic Review, 74(1): 5-31.

FONTAINE F. (2008b): "Why Are Similar Workers Paid Differently? The Role of Social Networks", Journal of Economic Dynamics and Control, 32: 3960-3977. 
GAUTIER P. A. (2002): "Unemployment and Search Externalities in a Model with Heterogeneous Jobs and Firms" Economica, 69: 21-40.

GAUTIER P.A., C.N.TEULINGS, A.VAN VUUREN (2010): "On-the-Job Search, Mismatch and Efficiency", Review of Economic Studies, 77(1): 245-272.

HALL R.E., A.B. KRUEGER (2008): "Wage Formation Between Newly Hired Workers and Employers: Survey Evidence", NBER Working Paper, 14329.

HAGEDORN M., I. MANOVSKII (2008): "The Cyclical Behavior of Equilibrium Unemployment and Vacancies Revisited", The American Economic Review, 98(4): 1692-1706.

HOFTMANN S., M. KÖNIG (2017): "Duales Studium in Zahlen 2016", AusbildungPlus.

HOSIOS A. (1990): "On the Efficiency of Matching and Related Models of Search and Unemployment", Review of Economic Studies, 57(2): 279-298.

JOLIVET G., F. POSTEL-VINAY, J.M. ROBIN (2006): "The Empirical Content of the Job Search Model: Labor Mobility and Wage Distributions in Europe and the US", European Economic Review, 50: 877-907.

LODOVICI M.S., S. COMI, F. ORIGO, M. PATRIZIO, N. TORCHIO, S. SPECKESSER, J. MONTALT (2013): "The Effectiveness and Costs-Benefits of Apprenticeships: Results of the Quantitative Analysis", European Commission.

MACHIN S., A. MANNING (1997): "Can Supply Create its Own Demand? Implications for Rising Skill Differentials", European Economic Review, 41: 507-516.

MANGIN S., B. JULIEN (2018): "Efficiency in Search and Matching Models: A Generalized Hosios Condition", Working Paper, Becker Friedman Institute.

MASUI M. (2011): "Jobs with Different Wage Determination Mechanism, Socially Efficiency and Unemployment", Journal of The Japanese and International Economies, 25: 56-75.

NAGYPAL E. (2008): "Worker Reallocation over the Business Cycle: The Importance of Employer-to-Employer Transitions", Working Paper, Northwestern University.

PETRONGOLO B., C.A. PISSARIDES (2001): "Looking into the Black Box: A Survey of the Matching Function ", Journal of Economic Literature, 39(2): 390-431.

PISSARIDES C.A (1994): "Search Unemployment with On-the-Job Search", Review of Economic Studies, 61: 457-476.

PISSARIDES C.A. (2000): "Equilibrium Unemployment Theory", The MIT Press, Cambridge.

RYAN P., K. WAGNER, S. TEUBER, U. BACKES-GELLNER (2011): "Financial Aspects of Apprenticeship Training in Germany, Great Britain and Switzerland", Working Paper, No 241.

SHIMER R. (2005): "The Cyclical Behavior of Equilibrium Unemployment and Vacancies", American Economic Review, 95: 25-49.

SHI S. (2002): "A Direct Search Model of Inequality with Heterogeneous Skills and SkillBiased Technology", Review of Economic Studies, 69(2): 467-491.

STUPNYTSKA Y., A. ZAHARIEVA (2017): "Optimal Policy and The Role of Social Contacts in a Search Model with Heterogeneous Workers", Journal of Public Economic Theory, $1-29$.

VAN DER VELDEN R., R. WELTER, M.WOLBERS (2001): "The Integration of Young People into The Labour Market within The European Union: The Role of Institutional Settings", 
Research Centre for Education and the Labour Market Working Paper, No 7. 